\title{
Transparency of Regulatory Data across the European Medicines Agency, Health Canada, and US Food and Drug Administration
}

\author{
Alexander C. Egilman, Amy Kapczynski, Margaret E. McCarthy, \\ Anita T. Luxkaranayagam, Christopher J. Morten, Matthew Herder, \\ Joshua D. Wallach, and Joseph S. Ross
}

Keywords: Transparency, Clinical Trials, Regulatory Data, Medical Product Regulation, Public Health

\begin{abstract}
Based on an analysis of relevant laws and policies, regulator data portals, and information requests, we find that clinical data, including clinical study reports, submitted to the European Medicines Agency and Health Canada to support approval of medicines are routinely made publicly available.
\end{abstract}

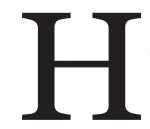
istorically, sponsors and regulatory agencies have kept confidential much of the clinical data generated to support the approval and continued monitoring of small molecule and biologic drugs (i.e., regulatory data). Notable cases, such as rofecoxib (Vioxx) and gabapentin (Neurontin), revealed how treating data as confidential can conceal important information about drug safety and efficacy, as well as improper research practices, including the selective publication and reporting of trial results. ${ }^{1}$ Providing access to these data may not only help prevent unscrupulous research practices, but also advance our understanding of the safety and effectiveness of medical products. ${ }^{2}$

Over the past two decades numerous initiatives have been launched to make regulatory data, including clinical study reports (CSRs) and individual patient-level data (IPD), publicly available. ${ }^{3}$ For instance, there are data sharing initiatives organized by industry (e.g. ClinicalStudyDataRequest. com [CSDR]) and independent organizations (e.g. Yale University Open Data Access [YODA] Project). ${ }^{4}$ While these efforts have advanced transparency for many medical products, ${ }^{5}$ they have not gained traction industry-wide and remain constrained by their lack of authority to require companies to make data publicly available. ${ }^{6}$ In contrast, regulatory agencies, as gatekeepers of market authorization, are best positioned to disclose data, particularly clinical data submitted for regulatory review.

Several laws and policies - some recent - authorize the European Medicines Agency (EMA) in Europe, Health Canada (HC) in Canada, and the Food and Drug Administration (FDA) in the United States

\footnotetext{
Alexander C. Egilman, B.A., is a Research Associate at the Collaboration for Research Integrity and Transparency at Yale Law School and the Center for Outcomes Research and Evaluation at Yale-Nere Haven Health System; Amy Kapczynski, M.Phil., M.A., J.D., is a Professor of Law at Yale Law School and Co-Director of the Collaboration for Research Integrity and Transparency and the Global Health Justice Partnership; Margaret E. McCarthy, M.A., J.D., Ph.D., is a Supervising Attorney at Brooklyn Defender Services; Anita T Luxkaranayagam, B.S., is a medical student at the University of Connecticut School of Medicine; Christopher J. Morten, J.D., Ph.D., is a Fellow of the Engelberg Center on Innovation Law Eं Policy and the Deputy Director of the Technology Law Eं Policy Clinic at Ner York University School of Law; Matthew Herder, LL.B., LL.M., J.S.M., is an Associate Professor in the Faculties of Medicine and Law at Dalhousie University and Director of Dalhousie University's Health Law Institute; Joshua D. Wallach, M.S., Ph.D., is an Assistant Professor of Epidemiology at Yale School of Public Health; Joseph S. Ross, M.H.S., M.D., is a Professor of Medicine (General Medicine) and of Public Health (Health Policy and Management) at the Yale School of Medicine, a member of the Center for Outcomes Research and Evaluation at Yale-Nere Haven Health System, and Co-Director of the National Clinician Scholars Program at Yale.
} 
to make clinical data of drugs publicly available, either proactively or reactively in response to information requests. These data (Box 1), such as clinical summaries, CSRs, individual case safety reports, and other information sponsors must submit to regulators, contain substantially more information than published articles and can be used to more comprehensively ascertain the risks and benefits of drugs, assess regulatory decisions, and inform clinical decision making. ${ }^{7}$

While regulatory data have been relied on for many studies, including systematic reviews and meta-analyses, ${ }^{8}$ there is substantial opportunity to increase use of regulatory data for secondary research. ${ }^{9}$ For example, one survey found that only $3 \%$ of authors of Cochrane
2010, authorizes the EMA to release data reactively. ${ }^{11}$ Policy 0070, adopted in 2014, authorizes the EMA to proactively publish data on an online data sharing portal. ${ }^{12}$ The scope of policy 0043 is expansive, providing access to any document originated, received, or held by the EMA. The scope of Policy 0070 is narrower, applying only to data submitted under the central marketing authorization procedure after January 1, 2015. EMA plans to implement Policy 0070 in two phases. Phase 1 publishes clinical reports, which include clinical overviews, clinical summaries, CSRs, along with several appendices to the CSRs, including protocol and protocol amendments, sample case report forms (CRFs), and statistical analysis plans

\section{In this analysis, we provide an overview of the key laws and policies governing disclosure of data at the EMA, HC, and FDA, including how each regulator defines certain data as "confidential commercial information" (CCI) that may be kept secret. Based on a review of agency data sharing portals, published research on information requests, and our own parallel information requests, we then compare the accessibility and comprehensiveness of data proactively disclosed and made available upon request by the EMA, HC, and FDA. Lastly, we propose ways for these regulatory bodies to enhance transparency.}

Reviews obtained data from regulatory agencies. ${ }^{10}$ Raising awareness of the scope of clinical data made available across the EMA, HC, and FDA, and the most efficient ways to obtain it, may increase the use and utility of clinical research data for patients, clinicians, and researchers.

In this analysis, we provide an overview of the key laws and policies governing disclosure of data at the EMA, HC, and FDA, including how each regulator defines certain data as "confidential commercial information" (CCI) that may be kept secret. Based on a review of agency data sharing portals, published research on information requests, and our own parallel information requests, we then compare the accessibility and comprehensiveness of data proactively disclosed and made available upon request by the EMA, HC, and FDA. Lastly, we propose ways for these regulatory bodies to enhance transparency.

\section{Transparency Laws and Policies European Medicines Agency}

Policy 0043 and Policy 0070 govern the EMA's approach to providing access to regulatory data for drugs and biologics (Table 1). Policy 0043, adopted in
(SAPs). Phase 2 will publish IPD. However, in 2018 EMA temporarily suspended its proactive publication of data, citing the disruption and resource constraints caused by the United Kingdom's withdrawal from the European Union. ${ }^{13}$

EMA's proactive and reactive disclosure policies take a similar position on CCI, generally considering information contained in clinical reports not as CCI, unless disclosure undermines the competitive position of the information's owner. This position faced several challenges in court but was recently validated by the European Court of Justice. The Court found that clinical reports were not covered by a general presumption of confidentiality and that market authorization holders must meet a high standard to qualify any data included in the reports as CCI, by establishing that disclosure poses the risk of concrete harm to their commercial interests. ${ }^{14}$ Additional details regarding data accessibility and the timeline for data publication are available in Table 1.

\section{Health Canada}

In March 2019, HC launched its Public Release of Clinical Information (PRCI) initiative, which goes beyond 
Box 1

Categories of regulatory data

\section{Type of document}

Clinical overview and clinical summary analysis of the clinical data submitted in the dossier.These documents present the strengths and limitations of the development program, analyze the benefits and risks of the medicinal product in its intended use, and describe how the study results support critical parts of the prescribing information.

Clinical study report

\section{Comprehensively describes the} methodology and results of a clinical trial. It contains more detail regarding trial design, conduct, and results than is contained in published versions of the same trial. It has several appendices, which include protocol and protocol amendments, sample case report forms, and statistical analysis plans.

\section{Protocol} and protocol amendments

Case report forms

\begin{tabular}{|l} 
Case report forms \\
\hline $\begin{array}{l}\text { Statistical analysis } \\
\text { plan }\end{array}$
\end{tabular}

\begin{tabular}{|l|} 
\\
\hline $\begin{array}{l}\text { Individual case } \\
\text { safety report }\end{array}$ \\
\hline $\begin{array}{l}\text { Individual patient- } \\
\text { level data }\end{array}$
\end{tabular}

\section{Describe the original objectives, design,} methods, statistical considerations and organization of a clinical trial, and include any subsequent protocol modifications. Both the protocol and later modifications are reviewed by an ethics committee.

Questionnaires used by the sponsor of the clinical trial to record information about each trial participant.

Provides a complete description of the planned methods for collection, analysis, interpretation, presentation, and organization of the data.

Provides detailed information related to a suspected adverse reaction to a medicinal product that occurs in a single patient at a specific point of time.

Individual data recorded for each participant in a clinical study, such as age, gender, race, efficacy and safety outcomes, laboratory results, etc.
Potential uses

- Provide insight into the quality and limitations of studies, issues encountered during product development and testing, and unusual prescribing information
- Appraise a trial and synthesize evidence, including evaluation of product safety and effectiveness

- Inform systematic reviews, meta-analyses, and risk of bias evaluations

- Provide greater detail than journal publications, which are often subject to word-count restrictions, particularly on secondary effectiveness endpoints and safety

- Determine improper research practices, such as datadredging, outcome switching, and selective reporting

- Assess study design and facilitate replication

- Identify unscrupulous research practices, such as outcome switching and P-hacking

- Ensure the accuracy of individual patient-level data

- Assess statistical methodology, including clinical trial power calculations, endpoint definitions, and proposed and conducted analyses

- Appraise and replicate statistical methods

- Identify an increase in the reporting of a known adverse event, a new serious adverse event not listed in a medicines label, or a new drug-drug interaction

- Appraise a trial and synthesize evidence, including for evaluation of product safety and effectiveness and for use in systematic reviews and meta-analyses

- Classify all adverse events when performing a meta-analysis focused on safety

- Perform relevant subgroup analyses

- Allow for longer follow-up compared to publications

- Perform time-to-event analyses

- Inform risk of bias evaluations

- Check the validity of previously reported findings

- Derive effects from data

- Standardize units of analyses

- Conduct more complex analyses

- Account for a wider range of covariates

- Answer secondary clinical questions

- Explore prognostic factors and surrogate outcomes

IPD=individual patient-level data.

aafinitions were adapted from EMA's definitions of regulatory data. ${ }^{37}$ 
EMA Policy 0070 by proactively releasing data for not only approved, unapproved, and withdrawn drug and biologic submissions but also Class III and IV medical device applications (Table 1). ${ }^{15}$ The clinical data made available is similar in scope to EMA Policy 0070, with $\mathrm{HC}$ publishing clinical reports. $\mathrm{HC}$ also intends to make clinical reports available upon request for medical products that had a final regulatory decision prior to March 2019, similar to Policy 0043. However, $\mathrm{HC}$ will not release IPD under the PRCI initiative. $\mathrm{HC}$ plans to phase in the proactive release of clinical reports over four years, beginning in 2019.

$\mathrm{HC}$ construes CCI (known as "confidential business information" in Canada) narrowly, protecting only clinical information not used by the applicant to support the proposed conditions of use or clinical information that describes tests, methods, or assays used exclusively by the manufacturer, and then only with adequate justification. ${ }^{16}$ Going forward, $\mathrm{HC}$ aims to publish data within 120 days after issuance of a final regulatory decision or after an information request is lodged. Unlike the EMA, data posted in response to information requests are made available on HC's online portal, requests are not limited to the citizens of the nation's regulator (i.e. Canadians), and registration is not required to access data.

\section{US Food and Drug Administration}

In January 2018, FDA launched a new pilot program to proactively publish CSRs of pivotal studies for nine recently-approved novel drugs, including trial protocols, protocol amendments, and SAPs (Table 1). ${ }^{17}$ However, FDA announced in March 2020 that it was ending the pilot, with only a single CSR having been made available. ${ }^{18}$

The Freedom of Information Act (FOIA), enacted in 1966, requires federal agencies, including the FDA, to disclose records upon request by the public, unless records fall under one of nine specific exemptions protecting interests such as CCI and personal privacy. ${ }^{19}$ FOIA is the only mechanism to access certain types of regulatory data, such as CSRs, for medical products approved by the FDA. ${ }^{20}$ The FDA has defined CCI as "valuable data or information which is used in one's business and is of a type customarily held in strict confidence or regarded as privileged and not disclosed to any member of the public by the person to whom it belongs." ${ }^{21}$ However, even if information meets the definition of CCI, FDA may have discretion to release it if there is a compelling public interest in disclosure. ${ }^{22}$

\section{Assessing Proactive Disclosure of Regulatory Data}

To assess the EMA and HC's proactive publication of clinical data under Policy 0070 and the PRCI initiative, respectively, we systematically searched each agency's online data sharing portal, ${ }^{23}$ documenting for each data release through April 2021: the type of medical product (drug, biologic, medical device, or vaccine); regulatory procedure (initial marketing authorization application (MAA) or post-authorization application); regulatory decision (approved, unapproved, or withdrawn); regulatory decision date; public release date; and time from regulatory decision to release. EMA and HC generally release the same categories of data across medical product types and regulatory procedures. Thus, to compare the data released across agencies, we randomly selected a single product for which both EMA and $\mathrm{HC}$ had made clinical data available, and then characterized the category of data released, number of pages, presence of redactions, reason for redactions provided (protected personal data (PPD) or CCI), and described the information redacted.

\section{Assessing Reactive Disclosure of Regulatory Data}

To assess EMA, HC, and FDA's reactive data disclosure processes, we first reviewed the literature to identify studies on information requests submitted to EMA, HC, or FDA. To better understand the scope of data made available by EMA, HC, and FDA in response to information requests, we submitted a FOIA request to FDA in 2014 for a wide range of clinical data and regulatory records for Gilead's Hepatitis C drugs sofosbuvir (Sovaldi) and ledipasvir/sofosbuvir (Harvoni) (Appendix Box 1), as well as a parallel request to EMA in 2016 under Policy 0043 and to HC in 2020 under the PRCI initiative. Sovaldi and Harvoni were selected as illustrative test cases because of their novelty, the safety issues that were being evaluated at the time we initiated this work, their use in the treatment of Hepatitis $\mathrm{C}$, a major global health problem, and high cost. ${ }^{24}$ We documented the date of each request milestone (e.g. initial request filed, appeal filed) and the date of each document production. For each production, we then characterized the category of data and the number of pages made available. We then described the information that had been redacted and compared the number of pages and redactions in CSRs of phase 2 and 3 trials produced by EMA, HC, and FDA.

Since HC releases information in response to requests on the same online data sharing portal as the information it proactively discloses, we followed the 


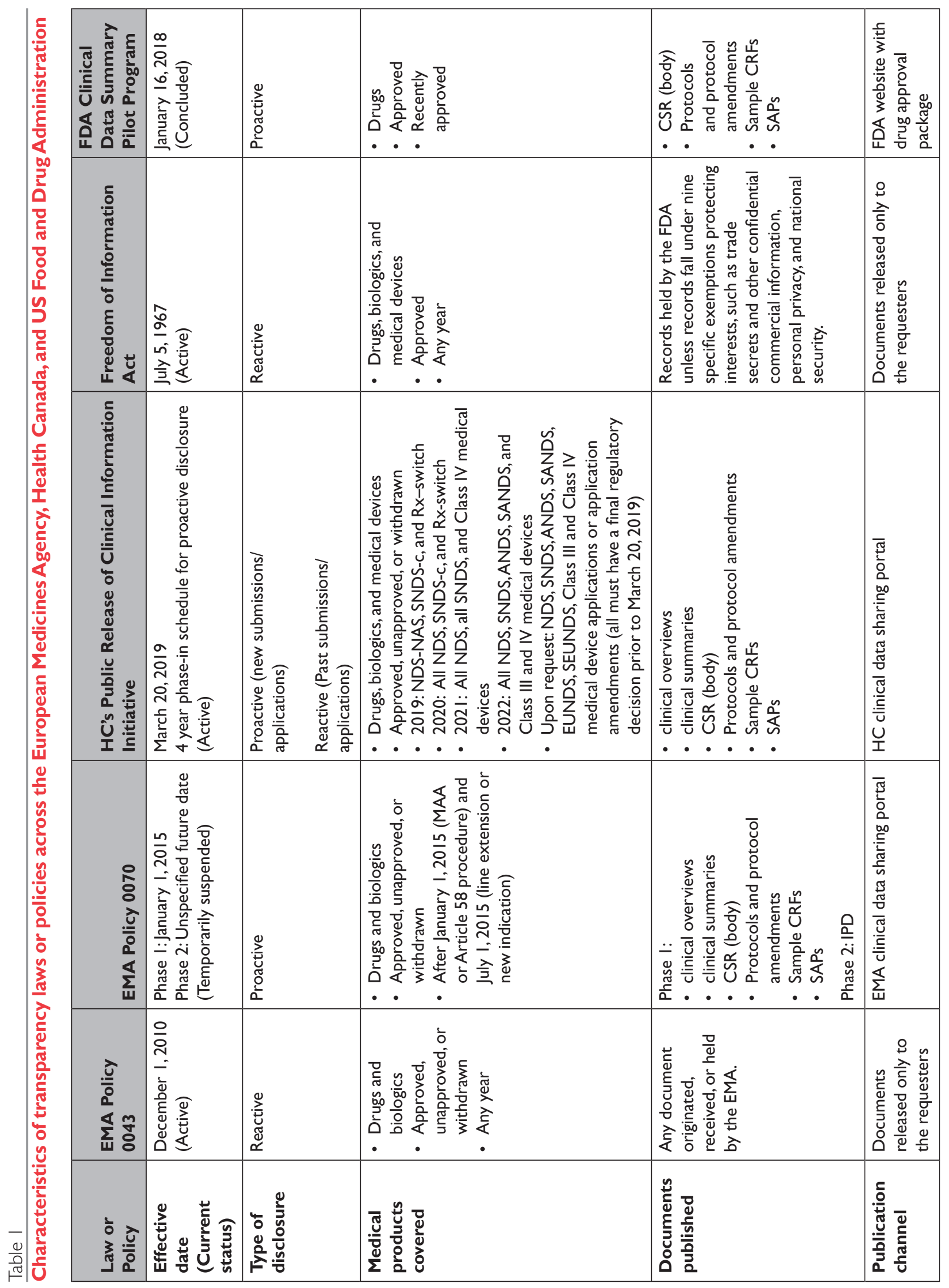




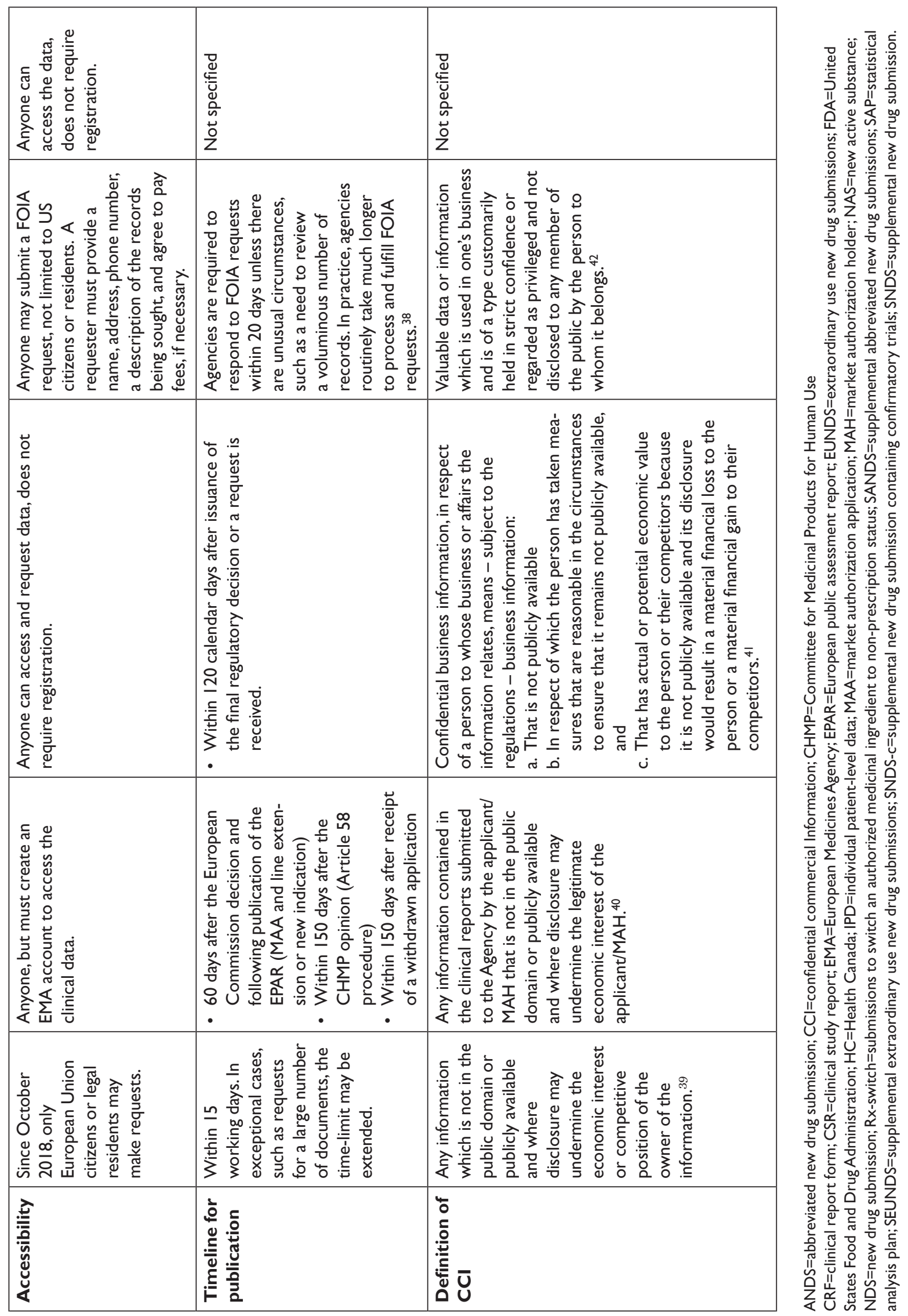


same methodology (described above) for extracting information on HC's reactive disclosure as we did for the agency's proactive disclosure.

\section{Findings: Proactive Disclosure of Regulatory Data}

Between 2016 and April 2021, EMA proactively released data for 123 unique medical products (Appendix Table 1), including 81 drugs, 38 biologics, and 4 vaccines (Table 2). Data supporting 147 regulatory procedures reviewed by the EMA between 2015 and 2021 were made publicly available, including 95 initial MAAs and 52 post-authorization applications; of which 135 were approved and 12 were withdrawn. Between 2019 and April 2021, HC proactively released data for 73 unique medical products, including 45 drugs, 23 biologics, 3 vaccines, and 2 medical devices. HC disclosed data supporting 62 initial MAAs and 13 post-authorization applications; all 75 were approved between 2016 and 2021. In 2018, FDA proactively disclosed data supporting the initial MAA of 1 drug that was approved in 2018. EMA, HC, and FDA took a median of 511 (interquartile range 416574), 150 (interquartile range 122-204), and 33 days, respectively, after each agency's regulatory decision to release data.

At the time of initial data collection (April 30, 2020), no data supporting the same MAA were proactively released by both EMA and HC. However, data supporting the same initial MAA for 4 medicines were made available proactively by EMA and reactively by HC. After reviewing HC's data releases and confirming the agency typically makes available equivalent categories of information proactively and reactively, we randomly selected daratumumab (Darzalex) among those 4 medicines to compare the information shared across EMA and HC. EMA and HC released 28 and 29 documents, respectively, for Darzalex, including all of the same categories of data: a clinical overview; summaries of biopharmaceutical and pharmacological studies, summaries of safety and efficacy, a biomarker technical report, and a population pharmacokinetic report; for each of its 5 clinical trials: a CSR ( 4 full, 1 synoptic), protocol and protocol amendments, sample CRFs, and SAPs for 3 of the trials (Table 3). There were no substantive discrepancies in the released data. However, EMA disclosed a more updated clinical overview, while $\mathrm{HC}$ posted an additional clinical overview addendum describing Canadian treatment approaches for multiple myeloma. The full CSRs, protocols, including those with amendments, CRFs, and SAPs had a median length of 1612, 108, 115, and 76 pages, respectively, for both EMA and HC. Redactions were comparable and minimal across EMA and $\mathrm{HC}$ :
PPD and CCI were provided as the reasons for redactions in 3 and 15 documents, respectively. Names of report investigators or subject ID numbers were the most common redactions.

\section{Findings: Reactive Disclosure of Regulatory Data}

We identified two studies on information requests to EMA under Policy 0043, no studies on information requests to $\mathrm{HC}$ under the PRCI initiative, one study on FOIA requests to FDA, and one study examining CSRs released in response to information requests to EMA and FDA, among other sources. One study determined that of the 457 information requests EMA received between 2010 and 2012, 66\% were granted, $27 \%$ were denied, and $7 \%$ were pending. ${ }^{25}$ Requests were processed in a median of 26 days. In a case series of 12 information requests filed between 2011 and 2015, the EMA released a wide variety of regulatory data, including CSRs, regulatory comments, meeting and decision records, periodic safety update reports, correspondence, and postmarket data and took a median of 301 days to process the requests. ${ }^{26} \mathrm{~A}$ study examining 78 CSRs, including 11 obtained from information requests to EMA and FDA, found that key appendices of CSRs, such as protocols and case report forms were frequently omitted. ${ }^{27}$ Based on a study of FOIA requests to FDA between 2008 and 2017, FDA fully or partially granted $72 \%$ of requests. ${ }^{28}$ FDA processed one-fifth of requests in 20 days but took more than 61 days to process two-thirds of requests.

$\mathrm{HC}$ released data for 55 unique medical products in response to 70 processed requests between February 2019 and April 2021, including for 23 drugs, 6 biologics, 6 vaccines, and 20 medical devices. $\mathrm{HC}$ took a median of 132 (interquartile range 103-167) days to process requests and published the same categories of regulatory data reactively as it had proactively.

In response to our parallel requests for information supporting approval of Sovaldi and Harvoni, FDA and $\mathrm{HC}$ released substantially more regulatory data than EMA, including clinical overviews, summaries and integrated summaries of safety and efficacy, clinical study protocols and amendments, and narratives of deaths and serious adverse events. Information only made available by FDA include individual safety case reports; records and correspondence related to product labeling, safety concerns, pediatric studies, expedited approval pathway designations, and postmarket study requirements and commitments; safety update reports; site initiation visit reports; and IPD, albeit heavily redacted (Appendix Table 2). Information only produced by $\mathrm{HC}$ include sample case report forms and statistical analysis plans (Appendix Table 3). 
Table 2

Characteristics of the medical products in which the European Medicines Agency, Health Canada, and US Food and Drug Administration have proactively made data available through April 202 I

\begin{tabular}{|c|c|c|c|}
\hline Regulatory Agency & EMA & $\mathrm{HC}$ & FDA \\
\hline \multicolumn{4}{|l|}{ Medical product type } \\
\hline Pharmacologic & 81 & 45 & 1 \\
\hline Biologic & 38 & 23 & 0 \\
\hline Medical device & 0 & 2 & 0 \\
\hline Vaccine & 4 & 3 & 0 \\
\hline \multicolumn{4}{|l|}{ Regulatory procedure } \\
\hline Initial marketing authorization ${ }^{\mathrm{b}}$ & 95 & 62 & 1 \\
\hline Post-authorization ${ }^{\mathrm{c}}$ & 52 & 13 & 0 \\
\hline \multicolumn{4}{|l|}{ Regulatory decision } \\
\hline Approved & 135 & 75 & 1 \\
\hline Unapproved & 0 & 0 & 0 \\
\hline Withdrawn & 12 & 0 & 0 \\
\hline \multicolumn{4}{|l|}{ Regulatory decision yeard } \\
\hline 2015 & 3 & 0 & 0 \\
\hline 2016 & 113 & 2 & 0 \\
\hline 2017 & 24 & 0 & 0 \\
\hline 2018 & 0 & I & I \\
\hline 2019 & 0 & 28 & 0 \\
\hline 2020 & 3 & 42 & 0 \\
\hline 2021 & 2 & 2 & 0 \\
\hline \multicolumn{4}{|l|}{ Data release year } \\
\hline 2016 & 6 & 0 & 0 \\
\hline 2017 & 58 & 0 & 0 \\
\hline 2018 & 78 & 0 & I \\
\hline 2019 & 0 & 10 & 0 \\
\hline 2020 & $\mathrm{Ie}^{\mathrm{e}}$ & 51 & 0 \\
\hline 2021 & $4^{e}$ & 14 & 0 \\
\hline $\begin{array}{l}\text { Median time from regulatory } \\
\text { decision to release }\end{array}$ & $\begin{array}{l}\text { 5II days }{ }^{d} \\
\text { (IQR 4I6-574) }\end{array}$ & $\begin{array}{l}\text { I50 days }{ }^{f} \\
\text { (IQR I22-204) }\end{array}$ & 33 days \\
\hline
\end{tabular}

$E M A=$ European Medicines Agency; FDA=United States Food and Drug Administration; $\mathrm{HC}=$ Health Canada; IQR=interquartile range.

aAlternative formulations were combined, along with generics or biosimilars with original products.

${ }^{b}$ For HC, initial marketing authorization includes new drug submission-new active substances $(n=42)$, new drug submissions $(n=15)$, Class III medical devices $(n=I)$, Class IV medical devices $(n=I)$, and 2 vaccines and I biologic authorized under Interim Order $(n=3)$. For FDA, initial marketing authorization includes I new drug application.

'For EMA, post-authorization includes extension of indications $(n=45)$, line extensions $(n=5)$, and workshare $(n=2)$ procedure types. For HC, postauthorization includes supplemental new drug submissions $(n=2)$ and supplemental new drug submissions containing confirmatory trials $(n=\mathrm{I})$. ${ }^{d}$ For EMA, dates of two post-authorization procedures were unavailable, and were excluded from processing time calculations. 'EMA's temporary suspension of Policy 0070 remains in place, however, clinical data for these 5 medical products were published in line with EMA's exceptional measures to maximize the transparency of its regulatory activities on treatments and vaccines for Coronavirus Disease 2019 that are approved or are under evaluation.

fOne biologic and one medical device package proactively released by $\mathrm{HC}$ were identified as part of the agency's pilot program and thus were excluded from processing time calculations. 


\begin{tabular}{|c|c|c|c|c|c|c|c|c|c|c|c|c|c|}
\hline 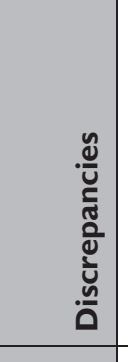 & 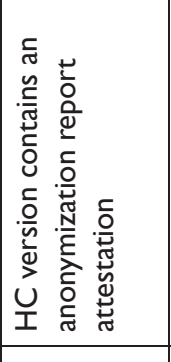 & $\not ̊$ & 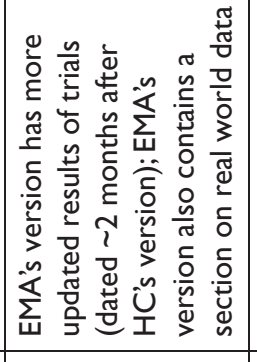 & $\not 2$ & $\stackrel{\circ}{z}$ & ż & $\stackrel{8}{z}$ & ż & ż & $\not 2$ & $\not ̊$ & $\stackrel{\circ}{z}^{\prime}$ & $\stackrel{\circ}{z}$ \\
\hline 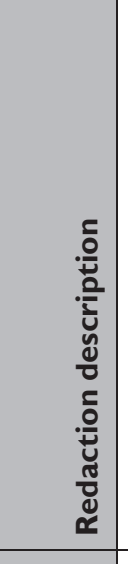 & $\underline{z}$ & 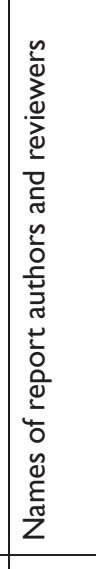 & 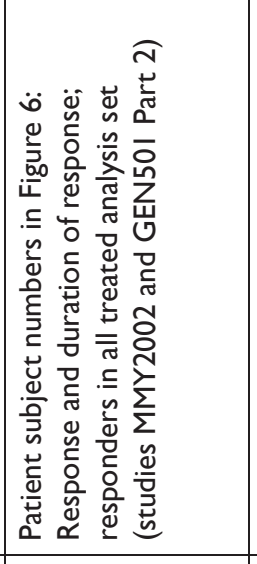 & $\underline{z}$ & $\underline{z}$ & 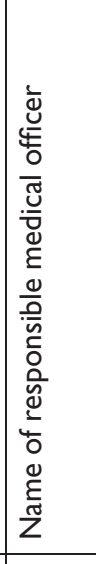 & 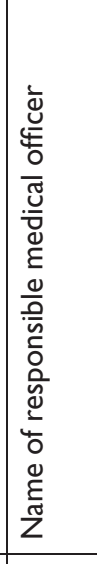 & 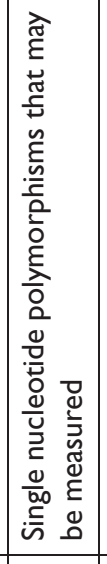 & 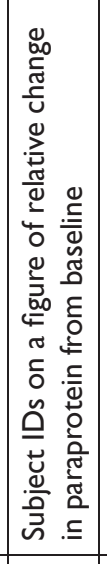 & 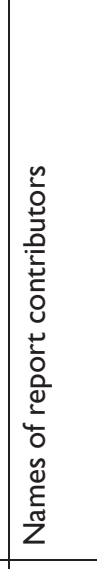 & 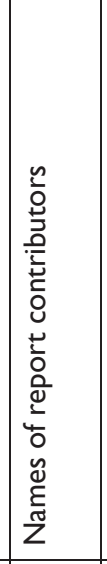 & 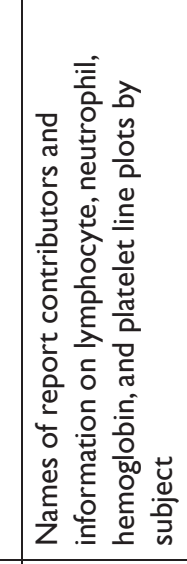 & 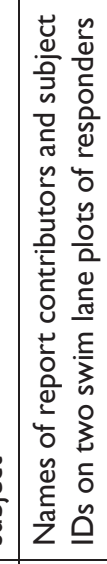 \\
\hline 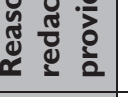 & $\underline{z}$ & $\frac{a}{2}$ & $\frac{a}{2}$ & $\frac{s}{z}$ & $\frac{\pi}{z}$ & 을 & $\frac{a}{a}$ & $\bar{U}$ & $\frac{a}{2}$ & a & $\frac{a}{2}$ & $\frac{a}{2}$ & $\frac{a}{2}$ \\
\hline 㐘 & zo & 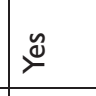 & 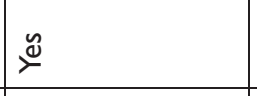 & z & ż & $\stackrel{\mathscr{u}}{\nu}$ & $\stackrel{\mathscr{x}}{\nu}$ & 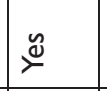 & $\stackrel{\mathscr{u}}{\nu}$ & $\stackrel{\mathscr{\vartheta}}{\nu}$ & 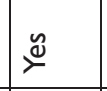 & $\stackrel{\mathscr{0}}{x}$ & 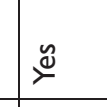 \\
\hline $\begin{array}{c}\substack{0 \\
\text { s. } \\
c^{\circ}} \\
\end{array}$ & 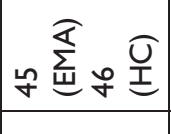 & q & হ & r & ณ & $\equiv$ & ฐి & I & $\stackrel{\infty}{\underline{\infty}}$ & $\underline{m}$ & $\underline{m}$ & \& & ఏ్ \\
\hline$\underline{\underline{y}}$ & 曰 & 曰 & В & 曰 & 曰 & В & В & 曰 & 曰 & 曰 & 曰 & 曰 & 曰 \\
\hline$\underset{\Psi}{\frac{\pi}{4}}$ & 曰 & 曰 & 曰 & $x$ & 曰 & 曰 & 曰 & 曰 & 曰 & 曰 & B & 曰 & 曰 \\
\hline $\begin{array}{l}\dot{0} \\
\mathbf{z} \\
\mathbf{z}\end{array}$ & & 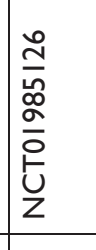 & & & 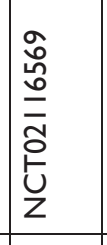 & 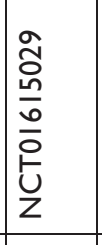 & 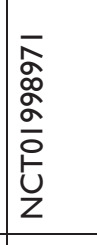 & 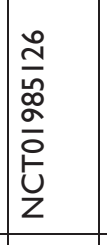 & 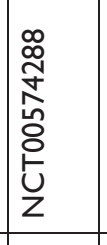 & 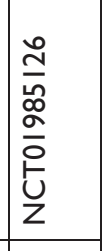 & 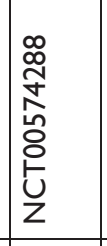 & 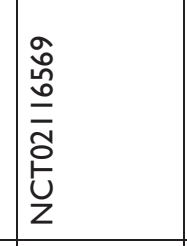 & 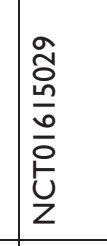 \\
\hline 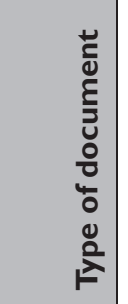 & 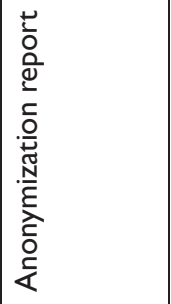 & 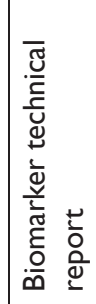 & & 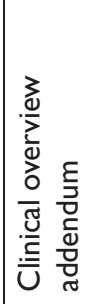 & 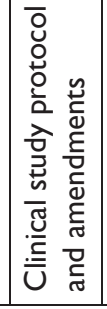 & 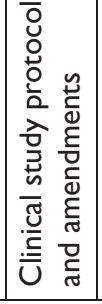 & 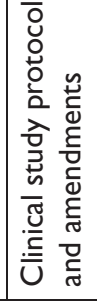 & 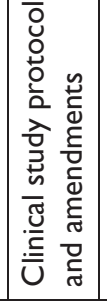 & 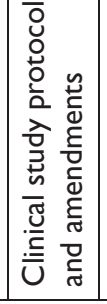 & 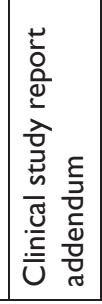 & 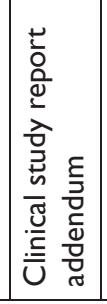 & 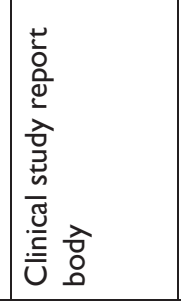 & 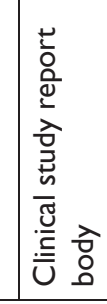 \\
\hline
\end{tabular}




\begin{tabular}{|c|c|c|c|c|c|c|c|c|c|c|c|c|c|c|c|}
\hline ¿ & ¿̀ & 을 & ㅇ & ㅇ & ㅇ & ㅇ & ํ & ㅇ & ㅇ & 으 & 을 & 을 & 을 & z & 으 \\
\hline ¿ & 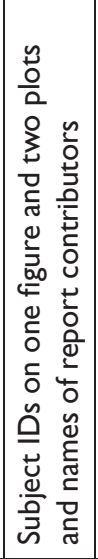 & 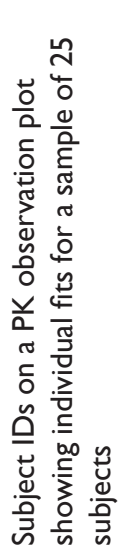 & ¿ & 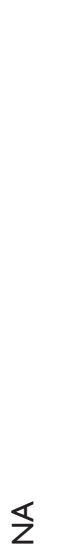 & ¿ & ¿ & ¿ & ¿ & 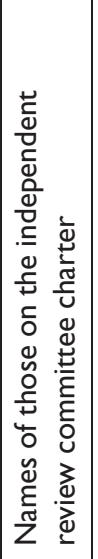 & 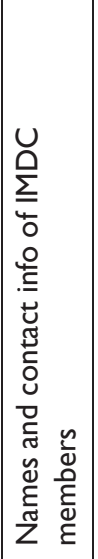 & 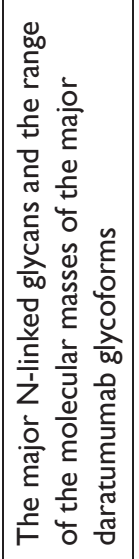 & 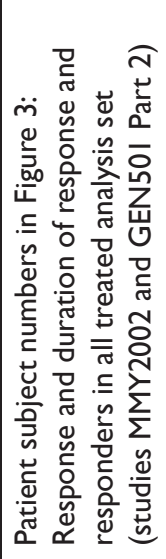 & 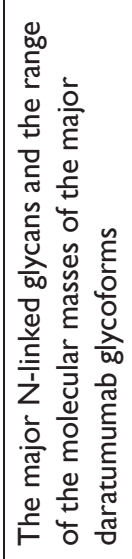 & 乙 & 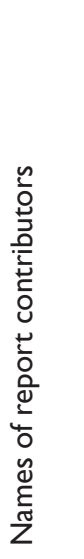 \\
\hline$\S$ & 음 & $\frac{0}{2}$ & 乙 & ¿ & ¿ & 乙 & $\S$ & $\S$ & 茜 & an & $\bar{U}$ & 믐 & $\bar{U}$ & $\S$ & $\frac{0}{a}$ \\
\hline 운 & $\stackrel{\check{\nu}}{\check{0}}$ & $\stackrel{y}{\check{\nu}}$ & 우 & zo & zo & zo & zo & ż & $\stackrel{\mathscr{\Perp}}{\check{\nu}}$ & $\stackrel{\check{\nu}}{\nu}$ & $\stackrel{y}{\nu}$ & $\stackrel{\check{\nu}}{\nu}$ & 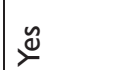 & zo & 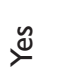 \\
\hline హి & : & $\stackrel{\circ}{\sim}$ & $\infty$ & $\stackrel{n}{\kappa}$ & $\stackrel{\infty}{0}$ & $\stackrel{\text { 느 }}{=}$ & นั & f & $\stackrel{ \pm}{\beth}$ & 10 & $\bar{N}$ & 웅 & $\infty$ & సิ & g \\
\hline$\Delta$ & $\Delta$ & $\Delta$ & 由 & $\Delta$ & $\Delta$ & $\Delta$ & $\nabla$ & $\nabla$ & $\Delta$ & $\Delta$ & $\Delta$ & $\Delta$ & $\Delta$ & $\nabla$ & $\Delta$ \\
\hline$\nabla$ & В & $\Delta$ & $\Delta$ & $\nabla$ & $\Delta$ & $\Delta$ & 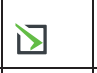 & $\nabla$ & $\Delta$ & $\Delta$ & $\nabla$ & $\Delta$ & $\nabla$ & $\nabla$ & $\nabla$ \\
\hline $\begin{array}{l}\frac{0}{2} \\
\frac{1}{2} \\
o \\
o \\
0 \\
z \\
z\end{array}$ & 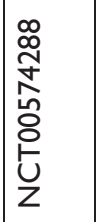 & & 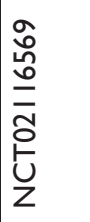 & 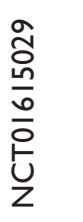 & 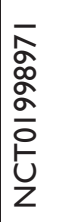 & 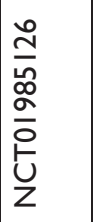 & 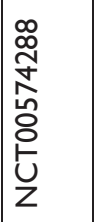 & 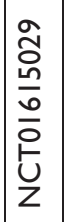 & 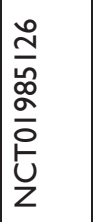 & 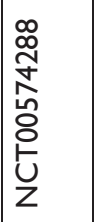 & & & & & 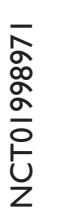 \\
\hline 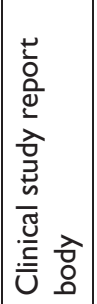 & 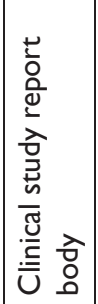 & 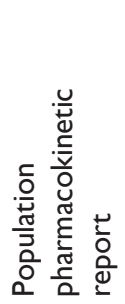 & 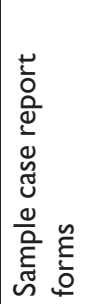 & 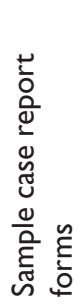 & 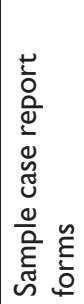 & 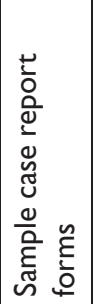 & 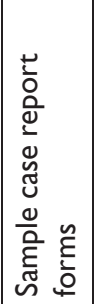 & 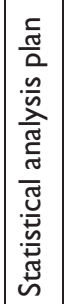 & 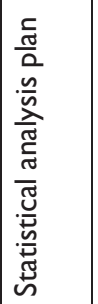 & 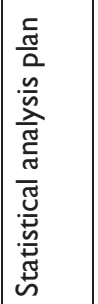 & 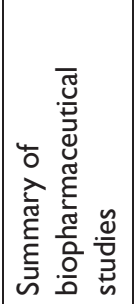 & 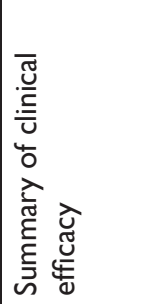 & 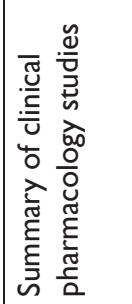 & 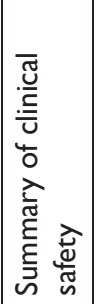 & 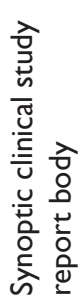 \\
\hline
\end{tabular}

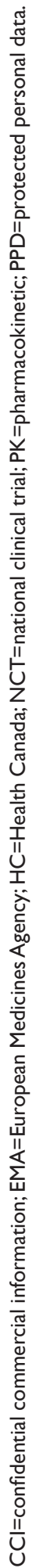


Information only made available by EMA include periodic safety update reports and pharmacovigilance risk assessment committee reports (Appendix Table 4).

All three agencies made available CSRs for phase 1, 2 , and 3 trials. Comparing the productions of CSRs of phase 2 and 3 clinical trials, EMA released CSRs corresponding to more phase 2 and 3 trials than FDA and HC ( 25 vs. 18 vs. 24 ); however, of the 16 CSRs produced for the same clinical trials by all three regulators, 11 released by FDA and HC were longer, 4 were the same, and 1 released by EMA was longer (Appendix Table 5). Among the 16 CSRs, those produced by FDA had an average of 473 pages compared to 464 and 179 pages for those produced by HC and EMA, respectively. EMA, HC, and FDA redactions of the CSRs were minimal, most commonly redacting names and contact information of study investigators and administrators and subject ID numbers. EMA and FDA also commonly redacted information about the drug manufacturer and supplier, citing CCI, while $\mathrm{HC}$ redacted narratives of deaths and serious adverse events, citing PPD. Time from initial request to final data production was 918 and 968 days for FDA and EMA, respectively (Appendix Table 6). While HC processed the information request much faster, publicly posting the data packages for Harvoni and Sovaldi 155 and 351 days, respectively, after the initial request. The request to FDA required considerably more resources, including multiple appeals and court filings. Additionally, FDA waived processing fees; however, the agency normally charges fees unless it is shown disclosure of the requested information is in the public interest. ${ }^{29}$ Last, HC organizes its data productions into categories, making the information much easier to navigate and process.

\section{Enhancing Regulatory Data Transparency in the 2020s}

Over the past decade, EMA and HC have greatly expanded the public availability of regulatory data, while FDA has lagged behind by not proactively publishing clinical reports. EMA and HC's routine publication of clinical reports, including clinical overviews and summaries, CSRs, protocols, sample CRFs, and SAPs, which just a decade ago had largely been treated by regulators as CCI, represents a paradigm shift in clinical trial transparency. HC's more recent PRCI initiative goes beyond EMA Policy 0070 in proactively posting clinical reports supporting medical device applications, not just drug and biologic MAAs. HC also offers the most efficient source of regulatory data, typically posting clinical reports about 5 months after a regulatory decision, nearly a year quicker than EMA, and processing most information requests in less than
5 months, about 150 days quicker than EMA takes to release requested regulatory data that are complex or voluminous. ${ }^{30}$ EMA and FDA required nearly three years to process our request for comprehensive regulatory data supporting the approvals of Sovaldi and Harvoni, substantially longer than EMA had previously taken to process requests for CSRs. ${ }^{31}$

While EMA and FDA processing times vary widely, ${ }^{32}$ our findings suggest there may be an opportunity for EMA and FDA to increase their processing speed to align with HC. The CSRs released upon request by FDA and HC were more than double the length of those produced by EMA, suggesting FDA and HC may source more comprehensive CSRs. A similar request to FDA may require greater resources than to EMA and HC. Nonetheless, use of EMA or FDA's information request processes may be necessary to gain access to other types of regulatory data, such as sponsorregulator correspondence. Consistent with findings from other recent studies, redactions across the agencies were mostly minor (e.g., primarily researcher and participant identifying information) and generally did not impede interpretation of the evidence. ${ }^{33}$ Two notable exceptions are FDA and HC's complete redaction of IPD and narratives of serious adverse events and deaths, respectively.

Our study has several limitations. First, HC's start date, the date when $\mathrm{HC}$ initiates the process to prepare information for public release, was used to calculate HC's processing time for information requests, not the actual date information requests were submitted, which is not publicly available. HC may take several weeks, and in some cases months, to begin processing requests, particularly when a request requires clarification or where paper records need to be digitized. Therefore, $\mathrm{HC}$ may take moderately longer than a median of 132 days to process requests. However, it is unlikely to impact the study's finding that $\mathrm{HC}$ is the most efficient source of clinical reports, given EMA required a median of 301 days to process a series of comparable information requests and $\mathrm{HC}$ also completed our requests for information on Sovaldi and Harvoni in about one-third the time that EMA and FDA required. ${ }^{34}$ Second, parts of the study were based on analyses of case studies, including Sovaldi, Harvoni, and Darzalex, which represent just a few of the many medical products for which data has been made publicly available. Third, the length of CSRs was used to compare the scope of data made available reactively by each agency; specific differences in the content of CSRs were not examined. Last, the study was limited to transparency of regulatory data, which comprises just a portion of data generated in clinical trials. Given the progress government agencies have made toward 
transparency of regulatory data, non-governmental led data sharing initiatives, such as the YODA Project, might consider shifting their focus and resources toward advancing data transparency of trials not submitted to regulators (e.g., academic trials).

While clinical reports and other categories of regulatory data supporting MAAs of drugs, biologics, and medical devices have been made accessible, there are several ways regulators could enhance transparency over the next decade. First, EMA and FDA should mitigate or remove barriers to accessing clinical reports, including citizenship requirements and processing costs associated with information requests, particularly for those requesting information in the public interest. Second, to improve access to information, EMA and FDA should post requested clinical data on should give greater priority and funding to regulatory data sharing programs. Concurrently, efforts to improve the efficiency of data sharing initiatives should be considered. For instance, multiregional disclosure requirements with varying anonymization standards for CCI and PPD increase costs. Regional regulators may consider a harmonized approach for clinical report disclosure to help reduce inefficiencies. In fact, $\mathrm{HC}$ has already begun accepting clinical information previously published under Policy 0070 for its PRCI initiative. Also, FDA recently announced that sharing of CSRs in harmony with international regulators is a long-term goal. ${ }^{36}$ However, an important benefit of a multiregional approach is that it encourages greater transparency by incentivizing sponsors to anonymize data in accordance with the standards least amenable

\section{In summary, regulatory data pertinent to public health and clinical medicine} that were used to support the approval of medicines and medical devices are now available proactively or in response to information requests. Over the next decade, regulatory agencies should make IPD available, and additional resources might be needed to ensure the long-term viability of regulatory data sharing programs and to encourage researchers to take advantage of the data that is - for now - more available than ever before.

a public online portal and increase their processing speed to more closely align with HC. To reduce delays, regulators should consider hiring more personnel and devoting greater resources to responding to requests. Third, EMA and FDA should extend access to data supporting medical devices. Last, while EMA remains committed to make available IPD in Phase 2 of Policy 0070, FDA and HC also should implement policies to share IPD, which would provide the raw data necessary to conduct secondary analyses. While sharing IPD poses increased risks of patient reidentification, data sharing initiatives, such as the YODA Project and CSDR, have demonstrated that through use of a "trusted intermediary," regulatory agencies could share IPD with researchers to maximize the use and utility of the data while still protecting patient privacy. ${ }^{35}$

The administrative and redaction costs incurred by industry and regulatory authorities represent a substantial obstacle to the future of clinical data sharing programs, exemplified by the ongoing, albeit temporary, suspension of Policy 0070 and the restriction of information requests to EMA to EU citizens and legal residents in 2018. To address this challenge, governments and institutions, such as the European Union, to CCI claims. For example, we found that names of drug manufacturers and suppliers were often redacted by EMA and FDA, but HC did not consider this information as CCI, and thus pharmaceutical sponsors may be encouraged to not devote resources to redact such information in a multiregional approach, recognizing the data will become public under the PRCI initiative. Therefore, it is important that measures, such as enforcement of HC's narrower definition of CCI, are taken to prevent harmonization of disclosure standards toward less transparency.

In summary, regulatory data pertinent to public health and clinical medicine that were used to support the approval of medicines and medical devices are now available proactively or in response to information requests. Over the next decade, regulatory agencies should make IPD available, and additional resources might be needed to ensure the long-term viability of regulatory data sharing programs and to encourage researchers to take advantage of the data that is - for now - more available than ever before. 


\section{Note}

Author Contributions: Mr. Egilman and Dr. Ross had full access to all the data in the study and take responsibility for the integrity of the data and the accuracy of the data analysis. ACE and JSR contributed to study concept and design; ACE, MEM, and ATL abstracted the data; all authors contributed to the analysis and interpretation of the data; ACE drafted the manuscript; all authors contributed to the critical revision of the manuscript; and JSR provided study supervision.

Additional Contributions: We thank John Brinkerhoff, Kathleen Choi, Nora Niedzielski-Eichner, Russell Fink, Darius Fullmer, Gregg Gonsalves, Cortelyou Kenney, Aislinn Klos, John Langford, Amanda Lynch, Jonathan Manes, Catherine Martinez, Yurji Melnyk, Ben Picozzi, Jennifer Pinsof, David Schulz, and Delbert Tran for their contributions to the information requests to EMA and FDA. These individuals pursued this work as students or faculty of Yale Law School and were not compensated for their efforts.

Funding: This project was conducted as part of the Collaboration for Research Integrity and Transparency (CRIT) at Yale, funded by the Laura and John Arnold Foundation, which formerly supported all of the authors. The Laura and John Arnold Foundation played no role in the design and conduct of the study; collection, management, analysis, and interpretation of the data; preparation, review, or approval of the manuscript; and decision to submit the manuscript for publication. The authors assume full responsibility for the accuracy and completeness of the ideas presented, which do not represent the views of any supporting institutions.

Competing interests: All authors have completed the ICMJE uniform disclosure form at www.icmje.org/coi_disclosure.pdf and declare: In the past 36 months, all of the authors formerly received research support through Yale University from the Laura and John Arnold Foundation for the Collaboration for Research Integrity and Transparency (CRIT) at Yale; Mr. Egilman and Drs. Ross and Wallach currently receive support from the Food and Drug Administration for the Yale-Mayo Clinic Center for Excellence in Regulatory Science and Innovation (CERSI) program (U01FD005938); Dr. Ross received research support through Yale University from Medtronic, Inc. and the Food and Drug Administration (FDA) to develop methods for postmarket surveillance of medical devices (U01FD004585) and from the Centers of Medicare and Medicaid Services (CMS) to develop and maintain performance measures that are used for public reporting (HHSM-500-2013-13018I); Dr. Ross currently receives research support through Yale University from Johnson and Johnson to develop methods of clinical trial data sharing, from the Medical Device Innovation Consortium as part of the National Evaluation System for Health Technology (NEST), from the Agency for Healthcare Research and Quality (R01HS022882), from the National Heart, Lung and Blood Institute of the National Institutes of Health (NIH) (R01HS025164, R01HL144644), and from the Laura and John Arnold Foundation to establish the Good Pharma Scorecard at Bioethics International. Mr. Herder is a member of the Patented Medicine Prices Review Board, Canada's national drug price regulator, and receives honoraria for his public service. Mr. Herder also receives research support from the Canadian Institutes of Health Research (PJT 156256; CMS 171741). Dr. Wallach receives support from the National Institute on Alcohol Abuse and Alcoholism of the National Institutes of Health under award K01AA028258.

Ethics approval: This study used publicly available information and did not require ethics approval from the Yale University School of Medicine Human Research Protection Program.

Data availability: Requests for the dataset can be made to the corresponding author at joseph.ross@yale.edu.

\section{References}

1. H.M. Krumholz, J.S. Ross, A.H. Presler, and D.S. Egilman, "What Have We Learnt from Vioxx?" BMJ 334 (2007): 120123; S.S. Vedula, L. Bero, R.W. Scherer, and K. Dickersin, "Outcome Reporting in Industry-Sponsored Trials of Gabapentin for Off-Label Use," New England Journal of Medicine 361, no. 20 (2009):1963-1971; A.C. Egilman, A.S. Kesselheim, H.M.
Krumholz, J.S. Ross, J. Kim, and A. Kapczynski, "Confidentiality Orders and Public Interest in Drug and Medical Device Litigation," JAMA Internal Medicine 180, no. 2 (2020):292299; A-W. Chan, F. Song, A. Vickers, T. Jefferson, K. Dickersin, P.C. Gøtzsche, et al., "Increasing Value and Reducing Waste: Addressing Inaccessible Research," The Lancet 383, no. 9913 (2014): 257-266.

2. L. Bernard, "Sharing Clinical Trial Data: Maximizing Benefits, Minimizing Risk," JAMA 313, no. 8 (2015): 793-794; J.S. Ross and H.M. Krumholz, "Ushering in a New Era of Open Science through Data Sharing: The Wall Must Come Down," JAMA 309, no. 13 (2013): 1355-1356; D. Eyding, M. Lelgemann, U. Grouven, M. Härter, M. Kromp, T. Kaiser, et al., "Reboxetine for Acute Treatment of Major Depression: Systematic Review and Meta-Analysis of Published and Unpublished Placebo and Selective Serotonin Reuptake Inhibitor Controlled Trials," BMJ 341 (2010): c4737; B. Wieseler, M.F. Kerekes, V. Vervoelgyi, N. McGauran, and T. Kaiser, "Impact of Document Type on Reporting Quality of Clinical Drug Trials: A Comparison of Registry Reports, Clinical Study Reports, and Journal Publications," BMJ 344 (2012): d8141; A.S. Paludan-Müller, P. Créquit, and I. Boutron, "Reporting of Harms in Oncological Clinical Study Reports Submitted to the European Medicines Agency Compared to Trial Registries and Publications - a Methodological Review," BMC Medicine 19, no. 1 (2021): 88.

3. P. Dey, J.S. Ross, J.D. Ritchie, N.R. Desai, S.P. Bhavnani, and H.M. Krumholz, "Data Sharing and Cardiology: Platforms and Possibilities," Journal of the American College of Cardiology 70 , no. 24 (2017): 3018-3025.

4. The Yale University Open Data Access (YODA) Project, available at <https://yoda.yale.edu/> (last visited July 27, 2021); ClinicalStudyDataRequest.com, available at <https://www. clinicalstudydatarequest.com/Default.aspx $>$ (last visited July 27, 2021)

5. M. Vaduganathan, A. Nagarur, A. Qamar, R.B. Patel, A.M Navar, E.D. Peterson, et al., "Availability and Use of Shared Data From Cardiometabolic Clinical Trials," Circulation 137, no. 9 (2018): 938-947; J.S. Ross, J. Waldstreicher, S. Bamford, J.A. Berlin, K. Childers, N.R. Desai, et al., "Overview and Experience of the YODA Project with Clinical Trial Data Sharing after 5 Years," Scientific Data 5, no. 1 (2018): 180268.

6. A.M. Hopkins, A. Rowland, and M.J. Sorich, "Data Sharing from Pharmaceutical Industry Sponsored Clinical Studies: Audit of Data Availability," BMC Medicine 16, no. 1 (2018): 165; B. Wieseler, N. McGauran, M.F. Kerekes, and T. Kaiser, "Access to Regulatory Data from the European Medicines Agency: The Times They Are a-Changing," Systematic Revieres 1, no. 1 (2012): 50 .

7. J.N. Schroll, E.I. Penninga, and P.C. Gøtzsche, "Assessment of Adverse Events in Protocols, Clinical Study Reports, and Published Papers of Trials of Orlistat: A Document Analysis," PLoS Medicine 13, no. 8 (2016): e1002101; P. Doshi, T. Jefferson, and C. Del Mar, "The Imperative to Share Clinical Study Reports: Recommendations from the Tamiflu Experience," PLoS Medicine 9, no. 4 (2012): e1001201; J.D. Wallach, K. Wang, A.D. Zhang, D. Cheng, H.K.G. Nardini, H. Lin, et al., "Updating Insights into Rosiglitazone and Cardiovascular Risk Through Shared Data: Individual Patient and Summary Level Meta-Analyses," BMJ 368 (2020): 17078; E.H. Turner, A.M. Mathews, E. Linardatos, R.A. Tell, and R. Rosenthal, "Selective Publication of Antidepressant Trials and its Influence on Apparent Efficacy," New England Journal of Medicine 358, no. 3 (2008): 252-260; J. Lexchin, J. Graham, M. Herder, T. Jefferson, and T. Lemmens, "Regulators, Pivotal Clinical Trials, and Drug Regulation in the Age of COVID-19," International Journal of Health Services 51, no. 1 (2021): 5-13.

8. T. Jefferson, M. Jones, P. Doshi, E.A. Spencer, I. Onakpoya, and C.J. Heneghan, "Oseltamivir for Influenza in Adults and Children: Systematic Review of Clinical Study Reports and Summary of Regulatory Comments," BMJ 346 (2013): f2231; L. Jørgensen, P.C. Gøtzsche, and T. Jefferson, "Benefits and Harms of the Human Papillomavirus (HPV) Vaccines: Sys- 
tematic Review with Meta-Analyses of Trial Data from Clinical Study Reports," Systematic Reviews 9, no. 1 (2020): 43; Paludan-Müller, supra note 2; Schroll, supra note 7.

9. A. Hodkinson, K.C. Dietz, C. Lefebvre, S. Golder, M. Jones, P. Doshi, et al., "The Use of Clinical Study Reports to Enhance the Quality of Systematic Reviews: A Survey of Systematic Review Authors," Systematic Reviewes 7, no. 1 (2018): 117; A.M. Navar, M.J. Pencina, J.A. Rymer, D.M. Louzao, and E.D. Peterson, "Use of Open Access Platforms for Clinical Trial Data," JAMA 315, no. 12 (2016): 1283-84; J.B. Schroll, L. Bero, and P.C. Gøtzsche, "Searching for Unpublished Data for Cochrane Reviews: Cross Sectional Study," BMJ 346 (2013): f2231; T. Jefferson, P. Doshi, I. Boutron, S. Golder, C. Heneghan, A. Hodkinson, et al., "When to Include Clinical Study Reports and Regulatory Documents in Systematic Reviews," BMJ Evidence-Based Medicine 23, no. 6 (2018): 210-17.

10. Schroll, supra note 9.

11. European Medicines Agency, Policy on Access to Documents (Policy 0043), October 4, 2018, available at <https://www. ema.europa.eu/en/documents/other/policy/0043-europeanmedicines-agency-policy-access-documents_en.pdf> (last visited June 27, 2021).

12. European Medicines Agency, Policy on Publication of Clinical Data for Medicinal Products for Human Use (Policy 0070), March 21, 2019, available at <https://www.ema.europa.eu/ en/documents/other/european-medicines-agency-policy-publication-clinical-data-medicinal-products-human-use_en.pdf> (last visited June 27, 2021).

13. European Medicines Agency, Brexit preparedness: EMA to further temporarily scale back and suspend activities, January 8, 2018, available at <https://www.ema.europa.eu/en/news/ brexit-preparedness-ema-further-temporarily-scale-back-suspend-activities> (last visited June 27, 2021).

14. Court of Justice of the European Union, PTC Therapeutics International Ltd $v$ EMA, Case C-175/18 P (judgement issued January 22, 2020), available at <http://curia.europa.eu/ juris/document/document.jsf?text $=\&$ docid $=222502 \&$ pageI ndex $=0 \&$ doclang $=\mathrm{EN} \&$ mode $=$ req\&dir $=\& o c c=$ first $\&$ part $=1 \&$ cid $=1894451>$ (last visited June 27, 2021).

15. Health Canada, Public Release of Clinical Information: guidance document, March 12, 2019, available at <https://www. canada.ca/en/health-canada/services/drug-health-productreview-approval/profile-public-release-clinical-informationguidance/document.html\#s1.1> (last visited June 27, 2021).

16. Health Canada, Guidance Document - Disclosure of Confidential Business Information under Paragraph 21.1(3)(c) of the Food and Drugs Act, March 12, 2019, available at <https:// www.canada.ca/en/health-canada/services/drug-health-product-review-approval/request-disclosure-confidential-businessinformation/disclosure-confidential-business-information/ guidance.html> (last visited June 27, 2021).

17. US Food and Drug Administration, FDA Commissioner Scott Gottlieb, M.D., on new steps FDA is taking to enhance transparency of clinical trial information to support innovation and scientific inquiry related to new drugs, January 16, 2018, available at <https://www.fda.gov/news-events/pressannouncements/fda-commissioner-scott-gottlieb-md-newsteps-fda-taking-enhance-transparency-clinical-trial> (last visited June 27, 2021).

18. US Food and Drug Administration, FDA Continues to Support Transparency and Collaboration in Drug Approval Process as the Clinical Data Summary Pilot Concludes, March 26, 2020, available at <https://www.fda.gov/news-events/pressannouncements/fda-continues-support-transparency-andcollaboration-drug-approval-process-clinical-data-summary> (last visited June 27, 2021)

19. 5 U.S.C. §552. Public information; agency rules, opinions, orders, records, and proceedings.
20. A.C. Egilman, J.D. Wallach, C.J. Morten, P. Lurie, and J.S Ross, "Systematic Overview of Freedom of Information Act Requests to the Department of Health and Human Services from 2008 to 2017," Research Integrity and Peer Review 4, no. 1 (2019): 26.

21. C.F.R. $\$ 20.61(b)(1994)$

22. A. Kapczynski and J. Kim, "Clinical Trial Transparency: The FDA Should and Can Do More," The Journal of Law, Medi cine, छ઼ Ethics 45, no. 2 (sup) (2017): 33-38; C.J. Morten and A. Kapczynski, "The Big Data Regulator, Rebooted: Why and How the FDA Can and Should Disclose Confidential Data on Prescription Drugs and Vaccines," California Law Review 109, no. 2 (2021): 493-558.

23. European Medicines Agency, Online Access to Clinical Data for Medicinal Products for Human Use, available at <https:// clinicaldata.ema.europa.eu/web/cdp/home> (last visited June 27, 2021); Health Canada, Search for clinical information on drugs and medical devices, available at $<\mathrm{https}$ ://clinical-information.canada.ca/search/ci-rc> (last visited June 27, 2021).

24. H. Fontaine, A. Lazarus, S. Pol, C. Pecriaux, F. Bagate, P. Sultanik, et al., "Bradyarrhythmias Associated with Sofosbuvir Treatment," The New England Journal of Medicine 373, no. 19 (2015): 1886-88; C. Scavone, L. Sportiello, C. Rafaniello, A. Mascolo, M. Sessa, F. Rossi, et al., "New Era in Treatment Options of Chronic Hepatitis C: Focus on Safety of New Direct-Acting Antivirals (DAAs)," Expert Opinion on Drug Safety 15, no. 2 (sup) (2016): 85-100; U. Spengler, "Direct Antiviral Agents (DAAs) - A New Age in the Treatment of

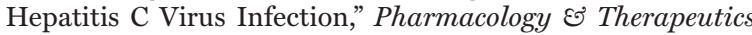
183 (2018): 118-26; J. Chhatwal, F. Kanwal, M.S. Roberts, and M.A. Dunn, "Cost-Effectiveness and Budget Impact of Hepatitis C Virus Treatment With Sofosbuvir and Ledipasvir in the United States," Annals of Internal Medicine 162, no. 6 (2015): 397.

25. P. Doshi and T. Jefferson, "The First 2 Years of the European Medicines Agency's Policy on Access to Documents: Secret no Longer," JAMA Internal Medicine 173, no. 5 (2013): 380-382.

26. P. Doshi and T. Jefferson, "Open Data 5 Years On: A Case Series of 12 Freedom of Information Requests for Regulatory Data to the European Medicines Agency," Trials 17, no. 1 (2016): 78.

27. P. Doshi and T. Jefferson, "Clinical Study Reports of Randomised Controlled Trials: An Exploratory Review of Previously Confidential Industry Reports," BMJ Open 3, no. 2 (2013): e002496.

28. Egilman, supra note 20

29. US Food and Drug Administration, FOLA Fees, available at $<$ https://www.fda.gov/regulatory-information/freedom-information/foia-fees $>$ (last visited June 27, 2021).

30. Doshi, supra note 26.

31. Doshi, supra note 26.

32. Egilman, supra note 20; Doshi, supra note 26.

33. Jefferson, supra note 8; Doshi, supra note 25; Doshi, supra note 26

34. Doshi, supra note 26.

35. C. Ohmann, R. Banzi, S. Canham, S. Battaglia, M. Matei, C. Ariyo, et al, "Sharing and Reuse of Individual Participant Data from Clinical Trials: Principles and Recommendations," BMJ Open 7, no. 12 (2017): e018647; Ross, supra note 5.

36. US FDA press release, supra note 18.

37. European Medicines Agency, Clinical data available, available at <https://clinicaldata.ema.europa.eu/web/cdp/background $\# 2>$ (last visited June 27, 2021).

38. Egilman, supra note 20.

39. EMA Policy O043, supra note 11.

40. EMA Policy OO7O, supra note 12.

41. Health Canada Guidance on CBI, supra note 16.

42. C.F.R. \$ 20.61, supra note 21. 


\section{Supplementary Appendix}

AppendixTable I

The medical products in which the European Medicines Agency, Health Canada, and US Food and Drug Administration have made data available through April 2021

\begin{tabular}{|c|c|c|c|}
\hline Generic Name (Brand) & EMA & $\mathrm{HC}$ & FDA \\
\hline 5-Aminolevulinic Acid (Ameluz) & 区 & $x$ & $x$ \\
\hline 840 PB Ventilator & $x$ & 区 (R) & $x$ \\
\hline Abatacept (Orencia) & 区 & $x$ & $x$ \\
\hline Abemaciclib (Verzenio) & $x$ & 区 $(\mathrm{P})$ & $x$ \\
\hline Abiraterone Acetate (Zytiga) & 区 & $x$ & $x$ \\
\hline Acalabrutinib (Calquence) & $x$ & 区 $(\mathrm{P})$ & $x$ \\
\hline Accu-Chek Inform II & $x$ & 区 (R) & $x$ \\
\hline Accu-Chek Inform II Test Strips & $x$ & 区 (R) & $x$ \\
\hline Accu-Chek Mobile Monitor & $x$ & 区 (R) & $\mathrm{x}$ \\
\hline Aceneuramic Acid (Kepnetic) & 区 & $x$ & $x$ \\
\hline Adalimumab (Humira) & 区 & $\mathrm{x}$ & $\mathrm{x}$ \\
\hline Afatinib (Giotrif) & 区 & $x$ & $x$ \\
\hline Albutrepenonacog Alfa (Idelvion) & 区 & $x$ & $x$ \\
\hline Alectinib (Alecensa) & 区 & $x$ & $x$ \\
\hline Alendronic Acid; Colecalciferol & 区 & $x$ & $x$ \\
\hline Alpelisib (Piqray) & $x$ & 区 (P) & $x$ \\
\hline Amifampridine (Firdapse) & $x$ & 区 $(\mathrm{P})$ & $x$ \\
\hline Amifampridine (Ruzurgi) & $x$ & 区 $(\mathrm{P})$ & $x$ \\
\hline Amlodipine;Valsartan & 区 & $x$ & $x$ \\
\hline Antihemophilic FactorViii (Esperoct) & $x$ & 区 $(\mathrm{P})$ & $x$ \\
\hline Apalutamide (Erleada) & $x$ & $x$ & 区 \\
\hline Aripiprazole & 区 & $x$ & $x$ \\
\hline Aripiprazole (Abilify Maintena) & $x$ & 区 (R) & $x$ \\
\hline Arsenic Trioxide (Trisenox) & 区 & $x$ & $x$ \\
\hline Asfotase Alfa (Strensiq) & $x$ & 区 $(\mathrm{P})$ & $x$ \\
\hline AT LISA tri & $x$ & 区 (R) & $x$ \\
\hline Atezolizumab (Tecentriq) & $x$ & 区 $(\mathrm{P})$ & $x$ \\
\hline Atorvastatin (Lipitor) & $x$ & 区 (R) & $x$ \\
\hline $\begin{array}{l}\text { Autologous CD34+ cells transfected with retroviral vector } \\
\text { containing adenosine deaminase gene (Strimvelis) }\end{array}$ & 区 & $x$ & $x$ \\
\hline Avelumab (Bavencio) & $x$ & 『 (P) & $\mathrm{x}$ \\
\hline Axicabtagene Ciloleucel (Yescarta) & $x$ & 区 (R) & $\mathrm{x}$ \\
\hline Baloxavir Marboxil (Xofluza) & $x$ & 区 (P) & $x$ \\
\hline Bamlanivimab & $\mathrm{x}$ & 区 (P) & $x$ \\
\hline Baricitinib (Olumiant) & 区 & $\mathrm{x}$ & $x$ \\
\hline
\end{tabular}




\begin{tabular}{|c|c|c|c|}
\hline Generic Name (Brand) & EMA & HC & FDA \\
\hline Baylis V4C-560 Ventilator & $x$ & 区 (R) & $x$ \\
\hline Begelomab (Begedina) & 区 & $x$ & $x$ \\
\hline Bevacizumab (Avastin) & 区 & $x$ & $x$ \\
\hline Bezlotoxumab (Zinplava) & 区 & $x$ & $x$ \\
\hline Bortezomib & 区 & $x$ & $x$ \\
\hline Brentuximab Vedotin (Adcetris) & $x$ & 区 $(P)$ & $x$ \\
\hline Brilliant Blue G (Tissueblue) & $x$ & 区 $(P)$ & $x$ \\
\hline Brolucizumab (Beovu) & $x$ & 区 $(P)$ & $x$ \\
\hline $\begin{array}{l}\text { Buprenorphine Hydrochloride; Naloxone Hydrochloride } \\
\text { Dihydrate (Suboxone) }\end{array}$ & $x$ & 区 (R) & $x$ \\
\hline CI Esterase Inhibitor (Cinryze) & 区 & $x$ & $x$ \\
\hline Cabozantinib (Cabometyx) & 区 & $x$ & $x$ \\
\hline Canakinumab (Ilaris) & 区 & $\mathrm{x}$ & $x$ \\
\hline Cannabidiol (Sativex) & $x$ & 『 (R\&P) & $x$ \\
\hline Caplacizumab (Cablivi) & $x$ & 区 $(\mathrm{P})$ & $x$ \\
\hline Carfilzomib (Kyprolis) & 区 & $\mathrm{x}$ & $\mathrm{x}$ \\
\hline Caspofungin Acetate & 区 & $\mathrm{x}$ & $x$ \\
\hline Cedazuridine; Decitabine (Inqovi) & $x$ & 区 (P) & $x$ \\
\hline Cediranib (Zemfirza) & 区 & $x$ & $x$ \\
\hline Ceftazidime;Avibactam (Zavicefta) & 区 & $x$ & $x$ \\
\hline Cemiplimab (Libtayo) & $x$ & 区 (P) & $x$ \\
\hline Chenodeoxycholic Acid & 区 & $x$ & $x$ \\
\hline Chlorhexidine (Umbipro) & 区 & $x$ & $x$ \\
\hline Chlormethine (Ledaga) & 区 & $x$ & $x$ \\
\hline Clomiphene Citrate (Serophene) & $x$ & 区 (R) & $x$ \\
\hline Conestat Alfa (Ruconest) & 区 & $x$ & $x$ \\
\hline Crizotinib (Xalkori) & 区 & $x$ & $x$ \\
\hline Cysteamine Bitartrate (Procysbi) & $\mathrm{x}$ & 区 (R) & $x$ \\
\hline Daclatasvir (Daklinza) & 区 & $x$ & $x$ \\
\hline Daclizumab (Zinbryta) & 区 & $x$ & $x$ \\
\hline Daptomycin (Cubicin) & 区 & $x$ & $x$ \\
\hline Daratumumab (Darzalex) & 区 & 区 (R) & $x$ \\
\hline Darolutamide (Nubeqa) & $x$ & 『 (P) & $x$ \\
\hline Darunavir & 区 & $x$ & $x$ \\
\hline Dasabuvir; Ombitasvir; Paritaprevir; Ritonavir (Cokiera) & 区 & $\mathrm{x}$ & $x$ \\
\hline Dasatinib (Apo-Dasatinib) & $\mathrm{x}$ & 『 (R) & $x$ \\
\hline Deferiprone (Ferriprox) & 区 & $\mathrm{x}$ & $x$ \\
\hline Deoxycholic Acid (Belkyra) & $x$ & 区 (R) & $x$ \\
\hline Dexamethasone phosphate (Dexamethasone Taw) & 区 & $x$ & $x$ \\
\hline
\end{tabular}


Appendix Table I (continued)

The medical products in which the European Medicines Agency, Health Canada, and US Food and Drug

Administration have made data available through April 202 I

\begin{tabular}{|c|c|c|c|}
\hline Generic Name (Brand) & EMA & $\mathrm{HC}$ & FDA \\
\hline $\begin{array}{l}\text { Diphtheria, Tetanus, Pertussis, Hepatitis B, Poliomyelitis, and } \\
\text { Haemophilus Influenzae Type-B Conjugate Vaccine (Infanrix } \\
\text { Hexa) }\end{array}$ & $x$ & 『(R) & $x$ \\
\hline $\begin{array}{l}\text { Diphtheria, Tetanus, Pertussis, Poliomyelitis Vaccine } \\
\text { (Adacel-Polio) }\end{array}$ & $x$ & 区(R) & $x$ \\
\hline Docetaxel & 区 & $x$ & $x$ \\
\hline Dolutegravir (Tivicay) & $x$ & 区 (R) & $x$ \\
\hline Drisapersen (Kyndrisa) & 区 & $x$ & $x$ \\
\hline Durvalumab (Imfinzi) & $x$ & 区 (P) & $x$ \\
\hline Edotreotide (SomaKit TOC) & 区 & $x$ & $x$ \\
\hline Eftrenonacog Alfa (Alprolix) & 区 & $x$ & $x$ \\
\hline Elbasvir; Grazoprevir (Zepatier) & 区 & $x$ & $x$ \\
\hline Elotuzumab (Empliciti) & 区 & $x$ & $x$ \\
\hline Eluxadoline (Truberzi) & 区 & $x$ & $x$ \\
\hline Empagliflozin (Jardiance) & 区 & $x$ & $x$ \\
\hline Empagliflozin; Linagliptin (Glyxambi) & 区 & $x$ & $x$ \\
\hline Emtricitabine; Rilpivirine;Tenofovir Alafenamide (Odefsey) & 区 & 『(R) & $x$ \\
\hline Emtricitabine; Tenofovir Alafenamide (Descovy) & 区 & $\mathrm{x}$ & $x$ \\
\hline Emtricitabine;Tenofovir Disoproxil (Truvada) & 区 & $\mathrm{x}$ & $x$ \\
\hline Enoxaparin Sodium (Thorinane; Inhixa) & 区 & $x$ & $x$ \\
\hline Entrectinib (Rozlytrek) & $x$ & 区 $(\mathrm{P})$ & $x$ \\
\hline Epoetin Alfa (Eprex) & $x$ & 区 (R) & $x$ \\
\hline Erdafitinb (Balversa) & $x$ & 区 $(\mathrm{P})$ & $x$ \\
\hline Eribulin (Halaven) & 区 & $x$ & $x$ \\
\hline Erlotinib (Tarceva) & 区 & $x$ & $\mathrm{x}$ \\
\hline Ertapenem & 区 & $x$ & $x$ \\
\hline Etelcalcetide (Parsabiv) & 区 & $x$ & $x$ \\
\hline Etomidate (Tomvi) & $x$ & 区 $(\mathrm{P})$ & $x$ \\
\hline Everolimus (Afinitor) & 区 & $x$ & $x$ \\
\hline Evolocumab (Repatha) & 区 & 区 (R) & $x$ \\
\hline Exablate 2100 & $x$ & 区 (R) & $x$ \\
\hline Fedratinib Hydrochloride (Inrebic) & $x$ & 区 (P) & $x$ \\
\hline Fluoxetine (Prozac) & $x$ & 区 (R) & $x$ \\
\hline Fluvastatin (Lescol) & $x$ & 区 (R) & $x$ \\
\hline Follitropin Delta (Rekovelle) & 区 & $x$ & $x$ \\
\hline Fostamatinib Disodium (Tavalisse) & $x$ & 区 (P) & $x$ \\
\hline Fotona Dynamis Laser System & $x$ & 『(R) & $x$ \\
\hline
\end{tabular}




\begin{tabular}{|c|c|c|c|}
\hline Generic Name (Brand) & EMA & HC & FDA \\
\hline Freestyle Libre Flash GMS & $x$ & 区 (R) & $x$ \\
\hline Fremanezumab (Ajovy) & $\mathrm{x}$ & 区 (P) & $\mathrm{x}$ \\
\hline Galcanezumab (Emgality) & $\mathrm{x}$ & 区 (P) & $\mathrm{x}$ \\
\hline Gallium Ga 68 Dotatate (Netspot) & $\mathrm{x}$ & 区 (P) & $\mathrm{x}$ \\
\hline Gemtuzumab Ozogamicin (Mylotarg) & $\mathrm{x}$ & 区 (P) & $\mathrm{x}$ \\
\hline Germanium Chloride; Gallium Chloride (Galliapharm) & $x$ & 区 $(\mathrm{P})$ & $x$ \\
\hline Gilteritinib Fumarate (Xospata) & $x$ & 区 (P) & $x$ \\
\hline Givosiran (Givlaari) & $x$ & 区 (P) & $x$ \\
\hline Glasdegib (Daurismo) & $x$ & 区 $(\mathrm{P})$ & $x$ \\
\hline Gynecare Gynemesh Ps & $x$ & 区 (R) & $x$ \\
\hline $\mathrm{Hel} / \mathrm{v}-\mathrm{l} / \mathrm{i}$ & $x$ & 区 $(\mathrm{P})$ & $x$ \\
\hline Human Coagulation Factor X (Coagadex) & 区 & $\mathrm{x}$ & $\mathrm{x}$ \\
\hline Human Normal Immunoglobulin (HyQvia) & 区 & $\mathrm{x}$ & $\mathrm{x}$ \\
\hline Human Papillomavirus 9-valent Vaccine (Gardasil 9) & $\mathrm{x}$ & 区 (R) & $\mathrm{x}$ \\
\hline $\begin{array}{l}\text { Human Papillomavirus Quadrivalent (Types 6, II, 16, 18) } \\
\text { Vaccine (Gardasil) }\end{array}$ & $x$ & 区 (R) & $x$ \\
\hline Ibrutinib (Imbruvica) & 区 & $x$ & $x$ \\
\hline Id Now Covid-19 & $\mathrm{x}$ & 区 (R) & $\mathrm{x}$ \\
\hline Idarucizumab (Praxbind) & 区 & $\mathrm{x}$ & $\mathrm{x}$ \\
\hline Idelalisib (Zydelig) & $x$ & 区 (P) & $x$ \\
\hline Infliximab (Flixabi) & 区 & $\mathrm{x}$ & $x$ \\
\hline Influenza Vaccine (Supemtek) & $x$ & 区 $(\mathrm{P})$ & $x$ \\
\hline Insulin Aspart (Fiasp) & 区 & 区 (R) & $x$ \\
\hline Insulin Aspart (Novorapid) & 区 & $x$ & $x$ \\
\hline Insulin Glargine (Lusduna) & 区 & $x$ & $x$ \\
\hline Insulin Human (Ryzodeg) & 区 & $x$ & $x$ \\
\hline Irinotecan Hydrochloride (Onivyde) & 区 & $x$ & $x$ \\
\hline Isatuximab (Sarclisa) & $x$ & 区 (P) & $x$ \\
\hline Ivabradine & 区 & $x$ & $x$ \\
\hline Ixazomib (Ninlaro) & 区 & $x$ & $x$ \\
\hline Ixekizumab (Taltz) & 区 & $x$ & $x$ \\
\hline Juvederm - Volbella & $x$ & 区 (R) & $x$ \\
\hline Lacosamide (Vimpat) & 区 & $x$ & $x$ \\
\hline Larotrectinib (Vitrakvi) & $x$ & 区 (P) & $x$ \\
\hline Ledipasvir; Sofosbuvir (Harvoni) & $x$ & 区 (R) & $x$ \\
\hline Lemborexant (Dayvigo) & $x$ & 区 $(\mathrm{P})$ & $x$ \\
\hline Lenvatinib (Kisplyx) & 区 & $x$ & $x$ \\
\hline Lesinurad (Zurampic) & 区 & $x$ & $x$ \\
\hline Linagliptin (Trajenta) & 区 & $x$ & $x$ \\
\hline
\end{tabular}


Appendix Table I (continued)

The medical products in which the European Medicines Agency, Health Canada, and US Food and Drug

Administration have made data available through April 202 I

\begin{tabular}{|c|c|c|c|}
\hline Generic Name (Brand) & EMA & $\mathrm{HC}$ & FDA \\
\hline Linagliptin; Metformin (Jentadueto) & 区 & $x$ & $x$ \\
\hline Liraglutide (Victoza) & 区 & $x$ & $x$ \\
\hline Lonoctocog Alfa (Afstyla) & 区 & 区 (Pilot) & $x$ \\
\hline Lutetium Chloride (EndolucinBeta) & 区 & $x$ & $x$ \\
\hline Mammomat Revelation & $x$ & 『 (Pilot) & $x$ \\
\hline Measles, Mumps and Rubella Vaccine (Priorix) & $x$ & 区 (R) & $\mathrm{x}$ \\
\hline $\begin{array}{l}\text { Measles, Mumps, Rubella, and Varicella Virus Vaccine } \\
\text { (Proquad) }\end{array}$ & $x$ & 区 (R) & $x$ \\
\hline $\begin{array}{l}\text { Meningococcal Group A, C, WI35, and Y Conjugate Vaccine } \\
\text { (Nimenrix) }\end{array}$ & 区 & $x$ & $x$ \\
\hline Methotrexate (Nordimet) & 区 & $x$ & $x$ \\
\hline Methylphenidate Hydrochloride (Foquest) & $x$ & 区 (R) & $x$ \\
\hline Metronidazole (Flagyl) & $x$ & 区 (R) & $x$ \\
\hline Migalastat (Galafold) & 区 & $x$ & $\mathrm{x}$ \\
\hline Moderna COVID-19 Vaccine & 区 & 区 $(P)$ & $\mathrm{x}$ \\
\hline Mona Lisa 10 Intrauterine Device & $\mathrm{x}$ & 区 (R) & $x$ \\
\hline Nelarabine (Atriance) & $x$ & 区 (P) & $x$ \\
\hline Nepafenac (Nevanac) & 区 & $x$ & $x$ \\
\hline Neratinib (Nerlynx) & $x$ & 区 (P) & $x$ \\
\hline Niraparib (Zejula) & $x$ & 区 (P) & $x$ \\
\hline Nivolumab (Opdivo) & 区 & 凹 (P) & $x$ \\
\hline Obeticholic Acid (Ocaliva) & 区 & $x$ & $x$ \\
\hline Obinutuzumab (Gazyvaro) & 区 & $x$ & $x$ \\
\hline Ofatumumab (Arzerra) & 区 & $\mathrm{x}$ & $\mathrm{x}$ \\
\hline Olaratumab (Lartruvo) & 区 & $\mathrm{x}$ & $x$ \\
\hline Osimertinib (Tagrisso) & 区 & $x$ & $x$ \\
\hline Oxycodone Hydrochloride (OxyContin and Oxyneo) & $x$ & 区 (R) & $x$ \\
\hline Ozanimod (Zeposia) & $x$ & 区 (P) & $x$ \\
\hline Palbociclib (Ibrance) & 区 & $x$ & $x$ \\
\hline Paliperidone (Trevicta) & 区 & $x$ & $x$ \\
\hline Palonosetron & 区 & $\mathrm{x}$ & $x$ \\
\hline Pancreas Powder (Enzepi) & 区 & $x$ & $x$ \\
\hline Pandemic Influenza Vaccine H5NI & 区 & $x$ & $x$ \\
\hline Patisiran (Onpattro) & $x$ & 区 (P) & $x$ \\
\hline Pembrolizumab (Keytruda) & 区 & 区 (P) & $x$ \\
\hline Pemetrexed & 区 & $x$ & $x$ \\
\hline Pemetrexed Diacid (Armisarte) & 区 & $x$ & $x$ \\
\hline
\end{tabular}




\begin{tabular}{|c|c|c|c|}
\hline Generic Name (Brand) & EMA & $\mathrm{HC}$ & FDA \\
\hline Pfizer-BioNTech COVID-I9 Vaccine & 区 & 区 (P) & $x$ \\
\hline Pirfenidone (Esbriet) & $x$ & 区 (R) & $x$ \\
\hline Plecanatide (Trulance) & $x$ & 区 $(\mathrm{P})$ & $x$ \\
\hline Polatuzumab Vedotin (Polivy) & $x$ & 区 $(\mathrm{P})$ & $x$ \\
\hline Prasterone (Intrarosa) & $x$ & 区 $(\mathrm{P})$ & $x$ \\
\hline Pravastatin (Pravachol) & $x$ & 区 (R) & $x$ \\
\hline Pregabalin & 区 & $x$ & $x$ \\
\hline Ranibizumab (Lucentis) & 区 & $x$ & $x$ \\
\hline Ranolazine (Corzyna) & $x$ & 区 $(\mathrm{P})$ & $x$ \\
\hline Rasagiline & 区 & $x$ & $x$ \\
\hline Ravulizumab (Ultomiris) & $x$ & 区 $(\mathrm{P})$ & $x$ \\
\hline Redexis & $x$ & 区 (R) & $x$ \\
\hline Remdesivir (Veklury) & 区 & 区 (P) & $x$ \\
\hline Reslizumab (Cinqaero) & 区 & $x$ & $x$ \\
\hline Rilpivirine; Cabotegravir (Cabenuva;Vocabria) & $x$ & 区 (P) & $x$ \\
\hline Riociguat (Adempas) & 区 & $\mathrm{x}$ & $\mathrm{x}$ \\
\hline Ripretinib (Qinlock) & $x$ & 区 $(\mathrm{P})$ & $x$ \\
\hline Risankizumab (Skyrizi) & $x$ & 区 $(\mathrm{P})$ & $x$ \\
\hline Rituximab (Truxima) & 区 & $x$ & $x$ \\
\hline Rociletinib (Xegafri) & 区 & $x$ & $x$ \\
\hline Romosozymab (Evenity) & $x$ & 区 (P) & $x$ \\
\hline Rosuvastatin Calcium (Crestor) & $x$ & 区 (R) & $x$ \\
\hline Rufinamide (Inovelon) & 区 & $x$ & $x$ \\
\hline $\begin{array}{l}\text { Salmeterol; Fluticasone Propionate (Aerivio Spiromax;Ai- } \\
\text { rexar Spiromax) }\end{array}$ & 区 & $x$ & $x$ \\
\hline Satralizumab (Enspryng) & $x$ & 区 $(\mathrm{P})$ & $x$ \\
\hline Saxagliptin; Dapagliflozin (Qtern) & 区 & $x$ & $x$ \\
\hline Sildenafil & 区 & $x$ & $x$ \\
\hline Simvastatin (Zocor) & $x$ & 区 (R) & $x$ \\
\hline Siponimod (Mayzent) & $x$ & 区 $(\mathrm{P})$ & $x$ \\
\hline Sodium Zirconium Cyclosilicate (Lokelma) & $x$ & 区 $(\mathrm{P})$ & $x$ \\
\hline Sofia SARS Antigen Fluorescent Immunoassay & $x$ & 区 (R) & $x$ \\
\hline Sofosbuvir (Sovaldi) & $x$ & 区 (R) & $x$ \\
\hline Sofosbuvir;Velpatasvir (Epclusa) & 区 & $x$ & $x$ \\
\hline Sonidegib (Odomzo) & $x$ & 区 $(\mathrm{P})$ & $x$ \\
\hline Spartan Covid-19 System & $x$ & 区 (R) & $x$ \\
\hline Spartan Covid-19V2 System & $x$ & 区 (R) & $x$ \\
\hline Tadalafil (Talmanco) & 区 & $x$ & $x$ \\
\hline Tafamidis Meglumine (Vyndaqel) & $x$ & 区 (P) & $x$ \\
\hline
\end{tabular}


Appendix Table I (continued)

The medical products in which the European Medicines Agency, Health Canada, and US Food and Drug

Administration have made data available through April 202 I

\begin{tabular}{|l|l|l|l|}
\hline Generic Name (Brand) & EMA & HC & FDA \\
\hline Talazoparib (Talzenna) & $\mathbf{X}$ & $\square(\mathrm{P})$ & $\mathbf{X}$ \\
\hline Tecnis Multifocal Intraocular Lens & $\mathbf{X}$ & $\square(\mathrm{R})$ & $\mathbf{X}$ \\
\hline Teduglutide (Revestive) & $\square$ & $\mathbf{X}$ & $\mathbf{X}$ \\
\hline Tenapanor (Ibsrela) & $\mathbf{X}$ & $\square(\mathrm{P})$ & $\mathbf{X}$ \\
\hline Tenofovir Alafenamide (Vemlidy) & $\square$ & $\mathbf{X}$ & $\mathbf{X}$ \\
\hline Tenofovir Disoproxil & $\square$ & $\mathbf{X}$ & $\mathbf{X}$ \\
\hline Teriparatide (Forteo; Movymio;Terrosa) & $\square$ & $\square(\mathrm{R})$ & $\mathbf{X}$ \\
\hline Tisagenlecleucel (Kymriah) & $\mathbf{X}$ & $\square(\mathrm{R})$ & $\mathbf{X}$ \\
\hline Tocilizumab (RoActemra) & $\square$ & $\mathbf{X}$ & $\mathbf{X}$ \\
\hline Trientine Hydrochloride (Mar-Trientine) & $\mathbf{X}$ & $\square(\mathrm{P})$ & $\mathbf{X}$ \\
\hline Trifarotene (Aklief) & $\mathbf{X}$ & $\square(\mathrm{P})$ & $\mathbf{X}$ \\
\hline Trifluridine;Tipiracil (Lonsurf) & $\square$ & $\mathbf{X}$ & $\mathbf{X}$ \\
\hline Tucatinib (Tukysa) & $\mathbf{X}$ & $\square(\mathrm{P})$ & $\mathbf{X}$ \\
\hline Upadactinb (Rinvoq) & $\mathbf{X}$ & $\square(\mathrm{P})$ & $\mathbf{X}$ \\
\hline Ustekinumab (Stelara) & $\square$ & $\mathbf{X}$ & $\mathbf{X}$ \\
\hline Venetoclax (Venclyxto) & $\square$ & $\square(\mathrm{P})$ & $\mathbf{X}$ \\
\hline $\begin{array}{l}\text { Vigileo Arterial Pressure Cardiac Output/Oximetry } \\
\text { Monitor }\end{array}$ & $\mathbf{X}$ & $\square(\mathrm{R})$ & $\mathbf{X}$ \\
\hline Vorapaxar (Zontivity) & $\square$ & $\mathbf{X}$ & $\mathbf{X}$ \\
\hline Voretigene Neparvovec (Luxturna) & $\mathbf{X}$ & $\mathbf{X}$ \\
\hline Xpert Xpress Sars-Cov-2 & $\mathbf{X}$ & $\mathbf{X}$ \\
\hline Zonisamide & $\square$ & $\mathbf{X}$ & \\
\hline
\end{tabular}

$E M A=$ European Medicines Agency; $F D A=$ United States Food and Drug Administration; $H C=$ Health Canada; $P=$ proactive; $R=$ reactive. 
Appendix Table 2

Summary of documents released by the US Food and Drug Administration in response to our Freedom of Information Act request

\begin{tabular}{|c|c|c|c|}
\hline $\begin{array}{l}\text { Production } \\
\text { No. }\end{array}$ & $\begin{array}{l}\text { Date of } \\
\text { Production }\end{array}$ & Pages & Document types \\
\hline 1 & $9 / 19 / 16$ & 10362 & Individual case safety reports \\
\hline 2 & $10 / 11 / 16$ & 503 & $\begin{array}{l}\text { Records related to fast track and breakthrough therapy designations; } \\
\text { memos of review cycle meetings and teleconferences between FDA and } \\
\text { Gilead; and FDA reviews }\end{array}$ \\
\hline 3 & $10 / 13 / 16$ & 8945 & $\begin{array}{l}\text { Clinical overviews; clinical safety summaries; clinical efficacy summaries; } \\
\text { integrated summaries of safety; integrated summaries of efficacy; interim } \\
\text { synoptic CSRs; and interim CSRs }\end{array}$ \\
\hline 4 & $10 / 18 / 16$ & 5894 & Clinical study protocols \\
\hline 5 & $10 / 27 / 16$ & 2372 & $\begin{array}{l}\text { Records and correspondence from new drug applications related to } \\
\text { product labeling, adverse events and safety issues, postmarketing require- } \\
\text { ments and commitments, mid- and late-cycle communications, and pro- } \\
\text { posed pediatric study requests; regulatory compliance audit reports; site } \\
\text { initiation visit reports; and safety update reports }\end{array}$ \\
\hline 6 & $11 / 2 / 16$ & 720 & $\begin{array}{l}\text { New drug application annual report, including annual status report of } \\
\text { postmarketing requirements and commitments }\end{array}$ \\
\hline 7 & $11 / 14 / 16$ & 9535 & Interim CSRs; interim synoptic CSRs; and final CSRs \\
\hline 8 & $11 / 18 / 16$ & 7979 & Clinical study protocols \\
\hline 9 & $12 / 23 / 16$ & 16840 & Final reports of animal studies \\
\hline 10 & $1 / 6 / 17$ & 10944 & $\begin{array}{l}\text { Records and correspondence from new drug applications, supplementary } \\
\text { new drug applications, and investigational new drug applications related } \\
\text { to product labeling, clinical investigator disclosures, sponsor requests for } \\
\text { pediatric study deferrals, FDA postmarketing requirement proposals, fast } \\
\text { track, breakthrough therapy, priority review designations, adverse events } \\
\text { and safety issues; clinical study protocols and protocol amendments }\end{array}$ \\
\hline 11 & $1 / 31 / 17$ & electronic files & IPD datasets \\
\hline 12 & $2 / 14 / 17$ & 6213 & Individual case safety reports \\
\hline 13 & $3 / 24 / 17$ & 1153 & Final clinical study report and an abbreviated clinical study report \\
\hline 14 & $4 / 6 / 17$ & electronic files & IPD datasets \\
\hline 15 & $6 / 22 / 17$ & electronic files & IPD datasets \\
\hline Total & & 81460 & \\
\hline
\end{tabular}

$C S R=$ clinical study report; FDA=United States Food and Drug Administration; IPD=individual patient-level data. 
Appendix Table 3

Summary of documents released by Health Canada in response to our information requests through the Public Release of Clinical Information initiative

\begin{tabular}{|c|c|c|c|}
\hline $\begin{array}{l}\text { Production } \\
\text { No. }\end{array}$ & $\begin{array}{l}\text { Date of } \\
\text { Production }\end{array}$ & Pages & Document Types \\
\hline I & $\begin{array}{l}7 / 31 / 20 \\
\text { (Harvoni) }\end{array}$ & 54052 & $\begin{array}{l}\text { Clinical overview; summary of biopharmaceutical studies and associated analytical meth- } \\
\text { ods; summary of clinical pharmacology studies; summary of clinical efficacy; summary } \\
\text { of clinical safety; comparative bioavailability and bioequivalence study reports; plasma } \\
\text { protein binding study reports; reports of hepatic metabolism and drug interaction stud- } \\
\text { ies; reports of studies using other human biomaterials; healthy subject PK and initial } \\
\text { tolerability study reports; patient PK and initial tolerability study reports; intrinsic factor } \\
\text { PK study reports; extrinsic factor PK study reports; population PK study reports; healthy } \\
\text { subject PD and PK/PD study reports; patient PD and PK/PD study reports; study reports } \\
\text { of controlled clinical studies pertinent to the claimed indication; integrated summary } \\
\text { of safety; integrated summary of efficacy, and other study reports. Most study reports } \\
\text { include a synopsis, report body, protocol and protocol amendments, sample case report } \\
\text { forms, and statistical analysis plans, and all study reports of Phase } 2 \text { and } 3 \text { trials also in- } \\
\text { cluded narratives of SAEs (albeit completely redacted) }\end{array}$ \\
\hline 2 & $\begin{array}{l}2 /|2 / 2| \\
\text { (Sovaldi) }\end{array}$ & 31466 & $\begin{array}{l}\text { Clinical overview; summary of biopharmaceutical studies and associated analytical meth- } \\
\text { ods; summary of clinical pharmacology studies; summary of clinical efficacy; summary } \\
\text { of clinical safety; comparative bioavailability and bioequivalence study reports; plasma } \\
\text { protein binding study reports; reports of hepatic metabolism and drug interaction stud- } \\
\text { ies; reports of studies using other human biomaterials; healthy subject PK and initial } \\
\text { tolerability study reports; patient PK and initial tolerability study reports; intrinsic factor } \\
\text { PK study reports; extrinsic factor PK study reports; population PK study reports; healthy } \\
\text { subject PD and PK/PD study reports; patient PD and PK/PD study reports; study reports } \\
\text { of controlled clinical studies pertinent to the claimed indication; integrated summary } \\
\text { of safety; integrated summary of efficacy, and other study reports. Most study reports } \\
\text { include a synopsis, report body, protocol and protocol amendments, sample case report } \\
\text { forms, and statistical analysis plans, and several study reports of Phase } 2 \text { and } 3 \text { trials also } \\
\text { included narratives of SAEs (albeit completely redacted). }\end{array}$ \\
\hline Total & & 85518 & \\
\hline
\end{tabular}

$\mathrm{PD}=$ pharmacodynamic; $\mathrm{PK}=$ pharmacokinetic; $\mathrm{SAE}=$ serious adverse event. 
Appendix Table 4

Summary of documents released by the European Medicines Agency in response to our information request under Policy 0043

\begin{tabular}{|c|c|c|c|}
\hline $\begin{array}{l}\text { Production } \\
\text { No. }\end{array}$ & $\begin{array}{l}\text { Date of } \\
\text { Production }\end{array}$ & Pages & Document Types \\
\hline 1 & $12 / 1 / 16$ & 102 & I final CSR \\
\hline 2 & $12 / 14 / 16$ & 322 & 2 PSURs, 2 PRAC reports \\
\hline 3 & $1 / 10 / 17$ & $147 \mid$ & 3 final CSRs \\
\hline 4 & $1 / 31 / 17$ & 476 & 2 final CSRs, I CSR amendment \\
\hline 5 & $2 / 21 / 17$ & 872 & I synoptic CSR, 2 final CSRs \\
\hline 6 & $3 / 27 / 17$ & 202 & 2 final CSRs, 2 CSR amendments \\
\hline 7 & $4 / 4 / 17$ & 338 & I interim CSR \\
\hline 8 & $5 / 4 / 17$ & 131 & I final CSR \\
\hline 9 & $5 / 30 / 17$ & 136 & 2 final CSRs, I CSR amendment \\
\hline 10 & $6 / 21 / 17$ & 204 & 2 final CSRs, I CSR amendment \\
\hline 11 & $7 / 12 / 17$ & 165 & 2 final CSRs, 2 CSR amendments \\
\hline 12 & $8 / 7 / 17$ & 254 & I final CSR, I interim CSR \\
\hline 13 & $9 / 13 / 17$ & 283 & 2 final CSRs, I tabular listing of clinical studies \\
\hline 14 & $10 / 4 / 17$ & 307 & 2 final CSRs \\
\hline 15 & $10 / 25 / 17$ & 396 & 3 interim CSRs \\
\hline 16 & $11 / 20 / 17$ & 492 & 3 interim CSRs \\
\hline 17 & $12 / 11 / 17$ & 99 & I interim CSR, I 2nd interim synoptic CSR \\
\hline 18 & $1 / 11 / 18$ & 132 & 2 abbreviated CSRs \\
\hline 19 & $2 / 7 / 18$ & 514 & 2 interim CSRs \\
\hline 20 & $3 / 7 / 18$ & 245 & I interim CSR, I interim synoptic CSR \\
\hline 21 & $4 / 20 / 18$ & 151 & I interim CSR, I interim synoptic CSR \\
\hline 22 & $5 / 28 / 18$ & 194 & 3 abbreviated CSRs \\
\hline 23 & $7 / 3 / 18$ & 578 & 2 final CSRs, I abbreviated CSR, I 2nd interim CSR \\
\hline 24 & $7 / 25 / 18$ & 50 & I PRAC \\
\hline 25 & $8 / 24 / 18$ & 373 & 2 PSURs, I PRAC report \\
\hline 26 & $9 / 20 / 18$ & 259 & I PSUR, I PRAC report \\
\hline 27 & $10 / 12 / 18$ & 274 & I PSUR, I PRAC report \\
\hline 28 & $11 / 21 / 18$ & 200 & I PSUR, I PRAC report \\
\hline 29 & $12 / 12 / 18$ & 258 & I PSUR, I PRAC report \\
\hline 30 & $1 / 14 / 19$ & 243 & I PSUR, I PRAC report \\
\hline 31 & $2 / 19 / 19$ & 244 & I PSUR, I PRAC report \\
\hline 32 & $3 / 12 / 19$ & 178 & I PSUR, I PRAC report \\
\hline 33 & $5 / 3 / 19$ & 107 & I final CSR \\
\hline 34 & $5 / 21 / 19$ & 242 & I 2nd interim CSR \\
\hline 35 & $6 / 20 / 19$ & 58 & 2 final synoptic CSRs \\
\hline 36 & $7 / 10 / 19$ & 371 & I 2nd interim CSR \\
\hline Total & & 10921 & \\
\hline
\end{tabular}

$C S R=$ clinical study report; $P R A C=$ pharmacovigilance risk assessment committee; PSUR=periodic safety update report. 


\begin{tabular}{|c|c|c|c|c|c|c|c|}
\hline 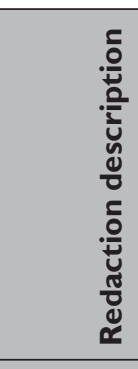 & 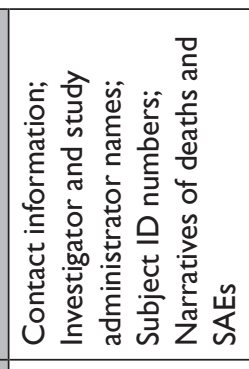 & 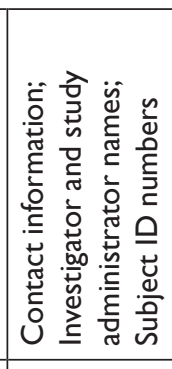 & 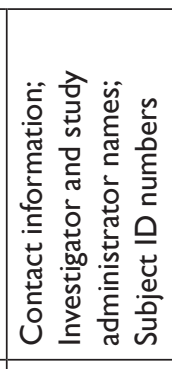 & 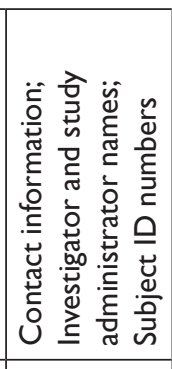 & & 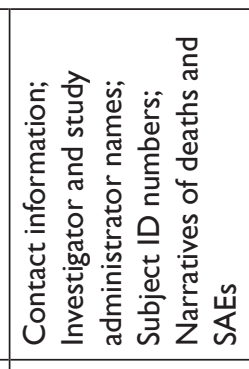 & 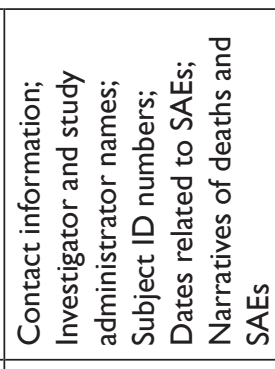 \\
\hline 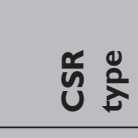 & 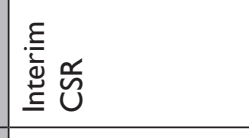 & 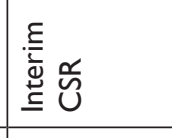 & 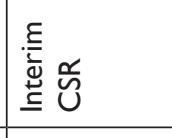 & 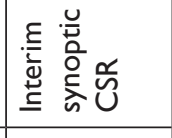 & & 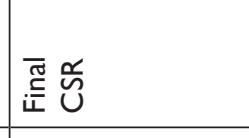 & 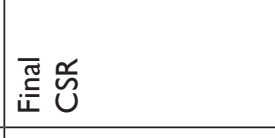 \\
\hline 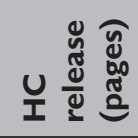 & 気 & 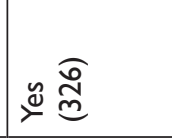 & 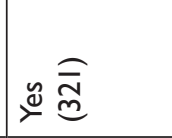 & $\stackrel{\mathscr{E}}{\mathscr{E}}$ & ż & 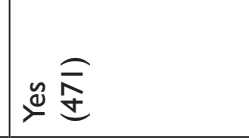 & 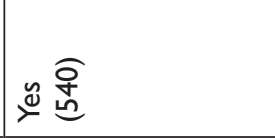 \\
\hline 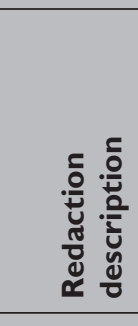 & 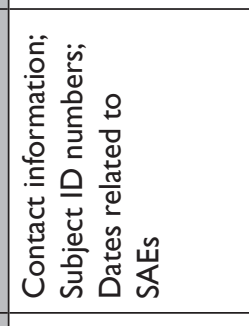 & 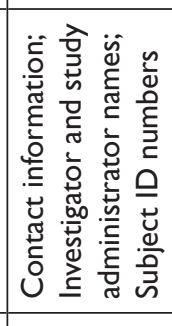 & 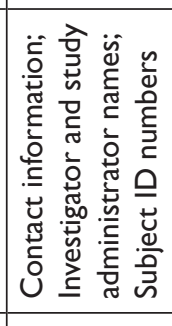 & 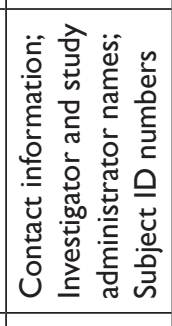 & 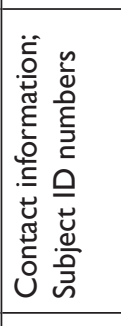 & 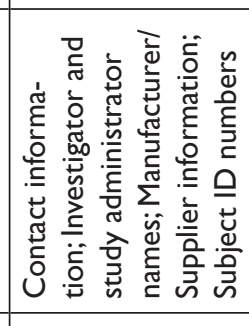 & 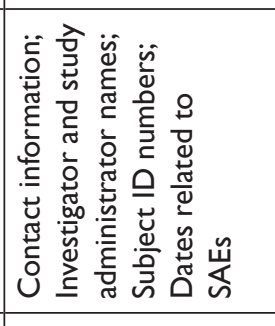 \\
\hline 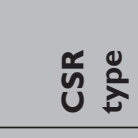 & 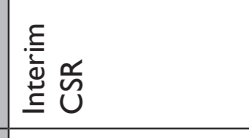 & 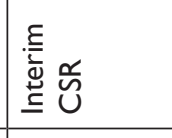 & 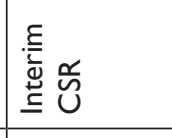 & 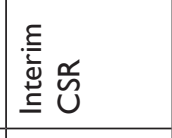 & 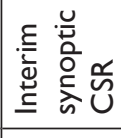 & 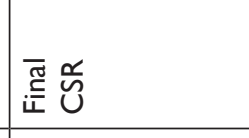 & $\begin{array}{l}\text { 嵒 } \\
\text { 递 }\end{array}$ \\
\hline 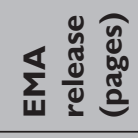 & 必 & $\underline{x} \underline{\underline{\underline{m}}}$ & 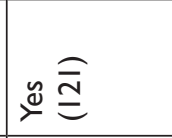 & $\stackrel{\varpi}{\approx} \widehat{\tilde{E}}$ & 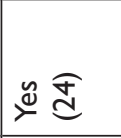 & 必 & 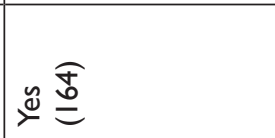 \\
\hline 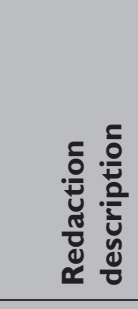 & 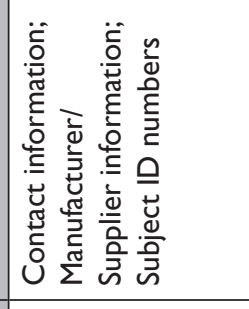 & 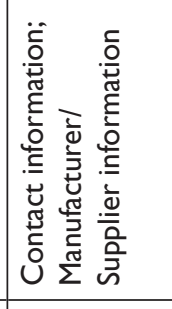 & 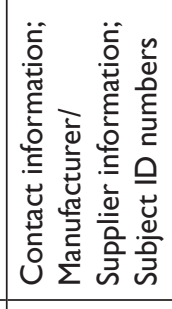 & 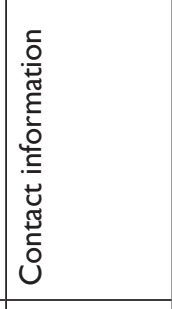 & 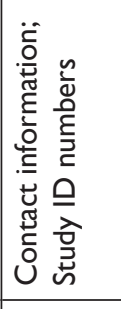 & 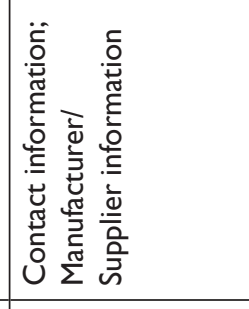 & 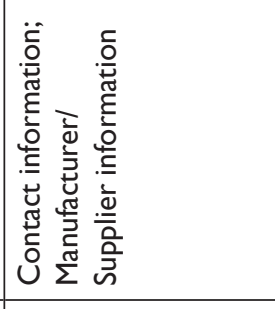 \\
\hline 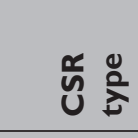 & $\begin{array}{l}\underline{E} \\
\text { 童 } \\
\underline{\underline{\underline{S}}} \\
\end{array}$ & 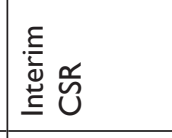 & 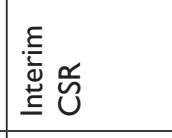 & 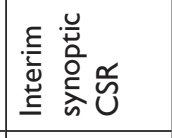 & 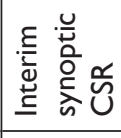 & 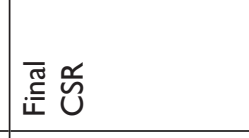 & \begin{tabular}{|l} 
嵒总 \\
\end{tabular} \\
\hline 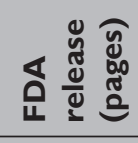 & 幽 总 & 幽 & 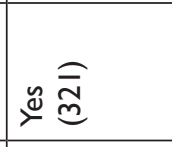 & $\stackrel{y}{\underline{x}} \widehat{\tilde{c}}$ & 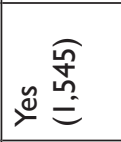 & 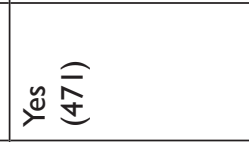 & 必高 \\
\hline 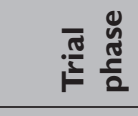 & $\equiv$ & $\equiv$ & $\equiv$ & $\equiv$ & $\equiv$ & $\cong$ & $\cong$ \\
\hline 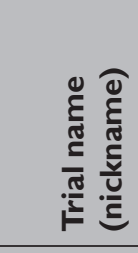 & 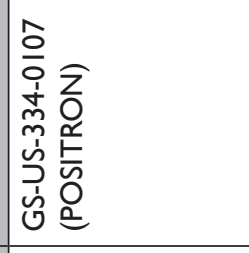 & 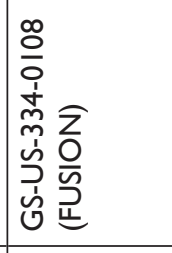 & 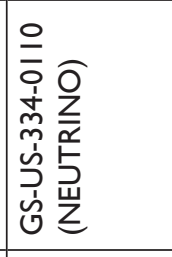 & 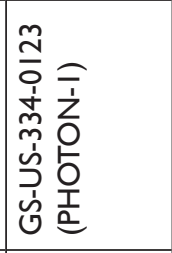 & 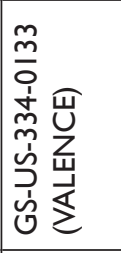 & 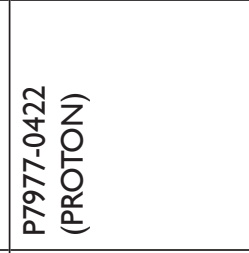 & 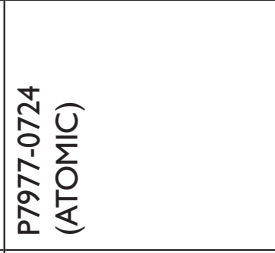 \\
\hline 哭 & 岕 & 岂 & 亗 & 亗 & 亗 & 岕 & 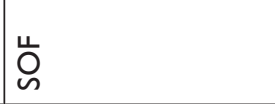 \\
\hline
\end{tabular}




\begin{tabular}{|c|c|c|c|c|c|}
\hline 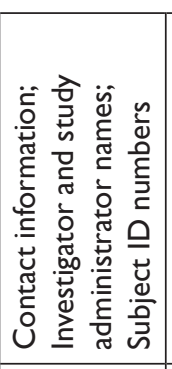 & 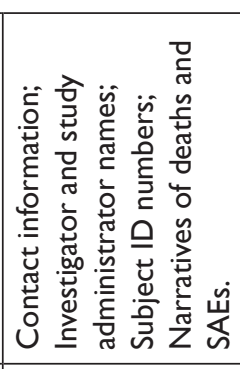 & 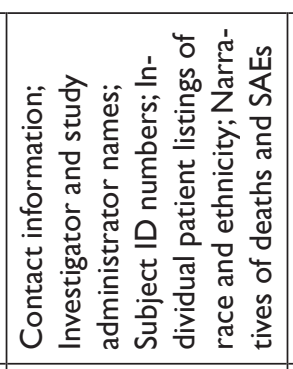 & 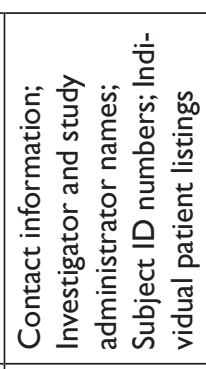 & 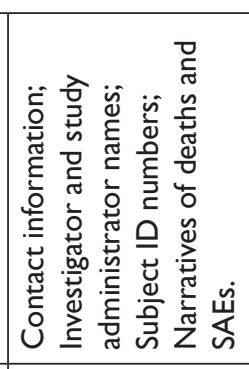 & 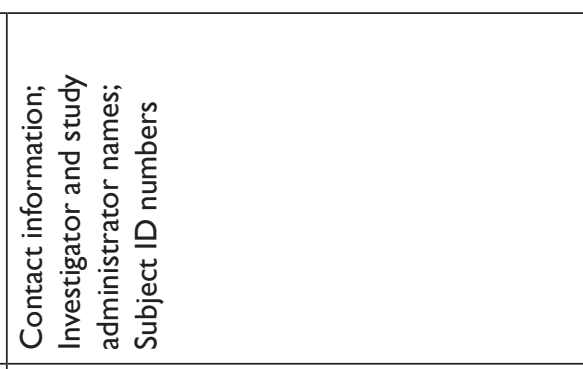 \\
\hline 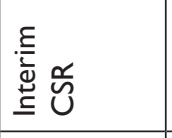 & 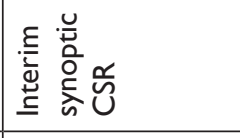 & 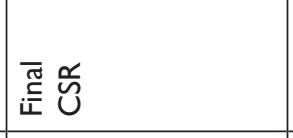 & 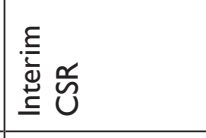 & 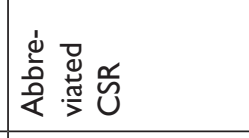 & 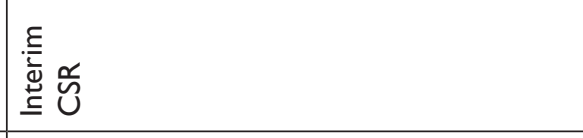 \\
\hline 兑高 & 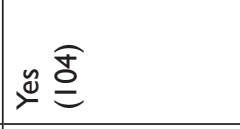 & 必 & 必产 & 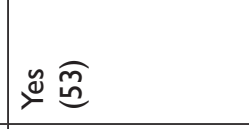 & 米 \\
\hline 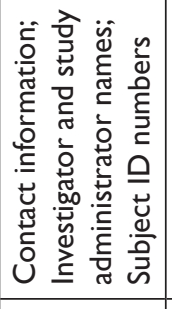 & 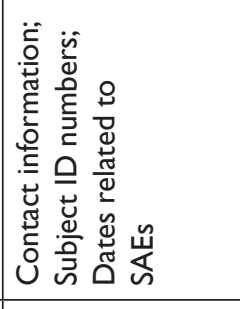 & & 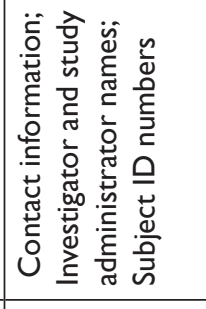 & 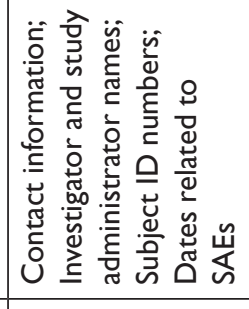 & 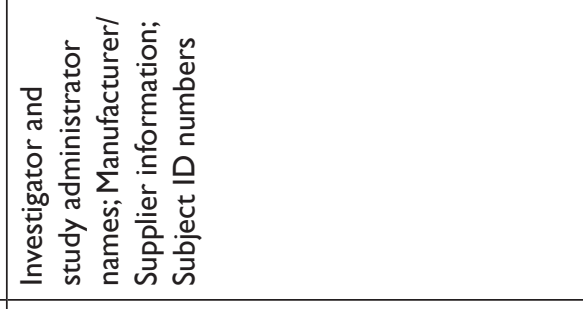 \\
\hline 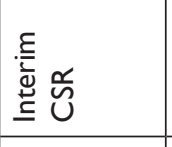 & 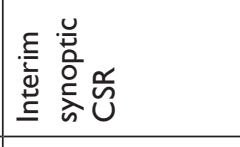 & & 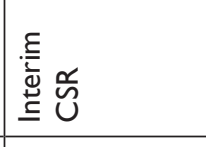 & 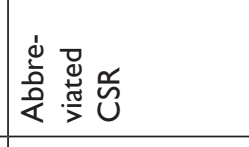 & 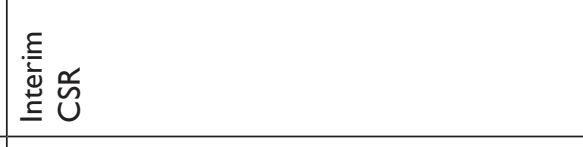 \\
\hline 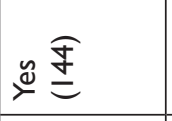 & 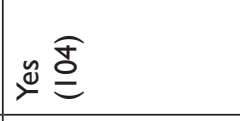 & 울 & 必 & 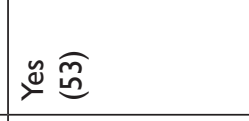 & 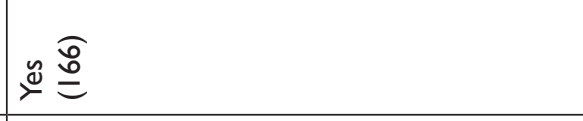 \\
\hline 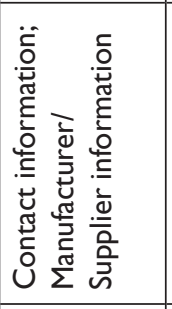 & 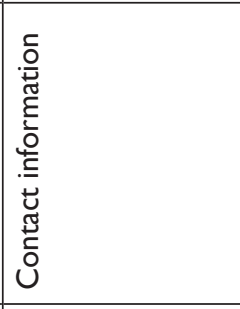 & 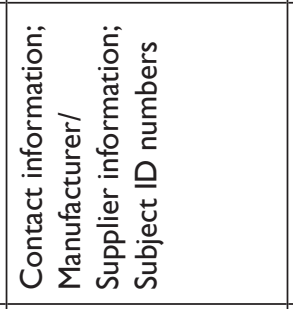 & & 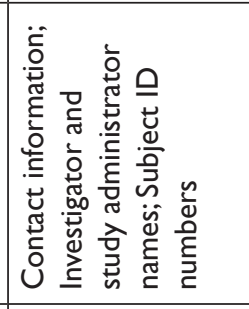 & 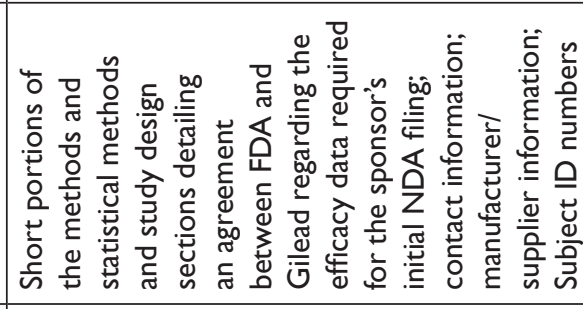 \\
\hline 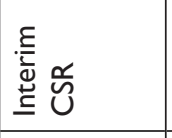 & 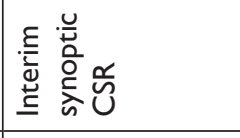 & 䟵 & & 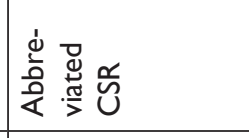 & 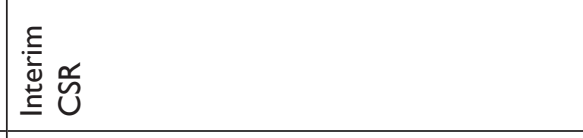 \\
\hline 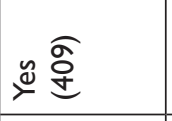 & 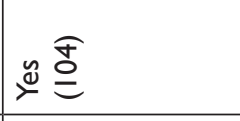 & 米 & 운 & 必 $\widehat{\underline{\beta}}$ & 幽 \\
\hline$\equiv$ & $=$ & $\leqq$ & $\equiv$ & $\leqq$ & $\equiv$ \\
\hline 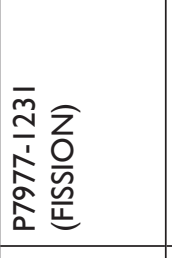 & 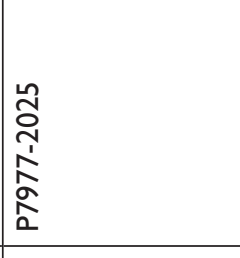 & 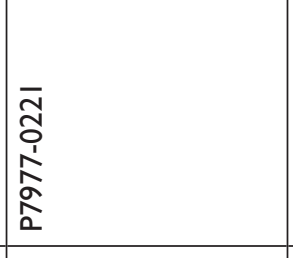 & 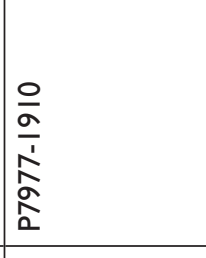 & 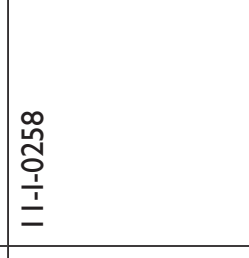 & 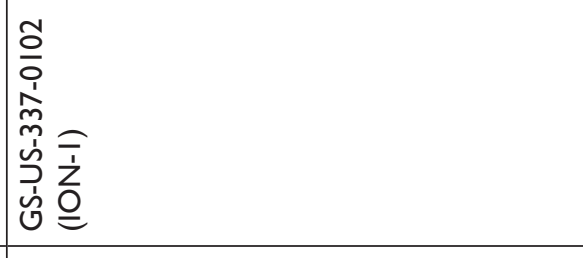 \\
\hline 亗 & 岁 & 岗 & 亗 & 岂 & 岀 \\
\hline
\end{tabular}




\begin{tabular}{|c|c|c|c|c|c|c|c|}
\hline 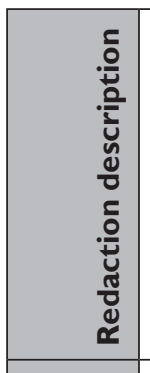 & 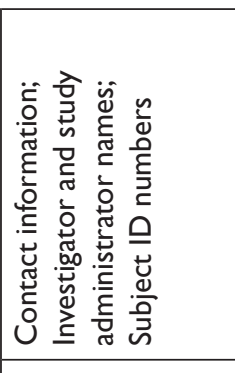 & 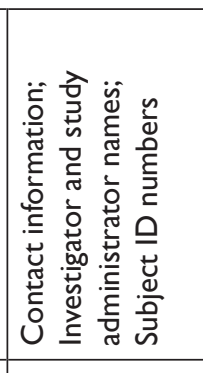 & 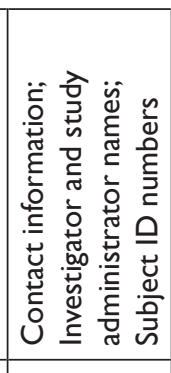 & 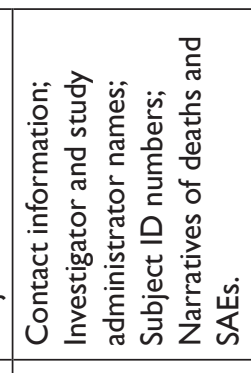 & 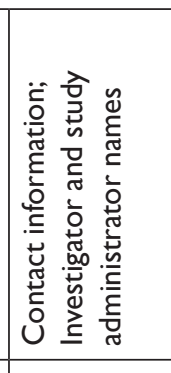 & & 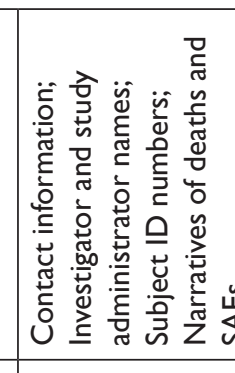 \\
\hline 号 & 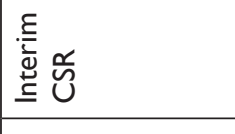 & 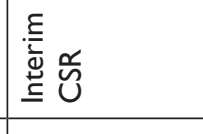 & 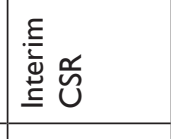 & 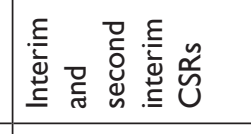 & 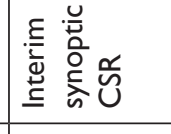 & & 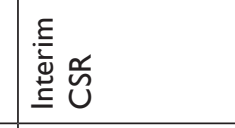 \\
\hline 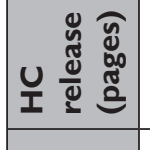 & 象 & 方垔 & 巡 & 気高 & 总舌 & $\stackrel{\circ}{2}$ & 里通 \\
\hline 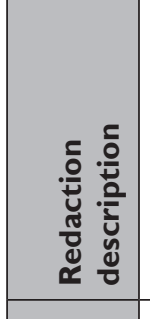 & 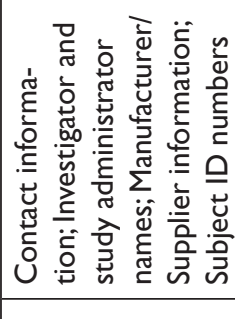 & 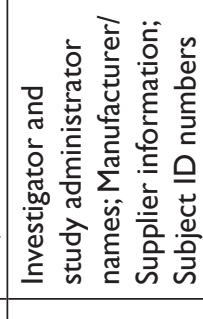 & 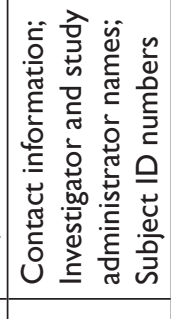 & 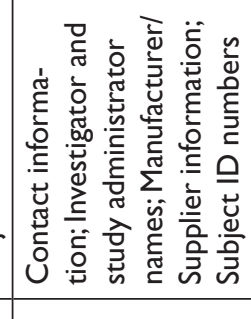 & 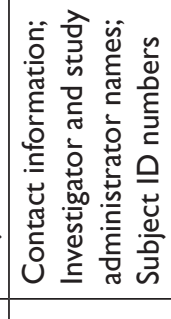 & 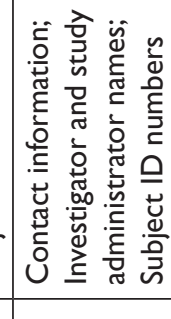 & 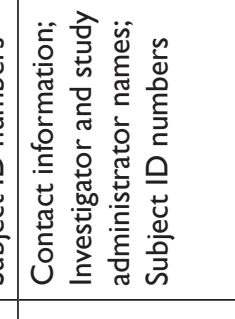 \\
\hline 我号 & 童号 & 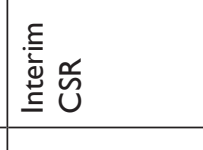 & 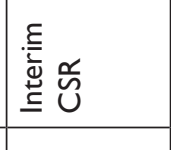 & 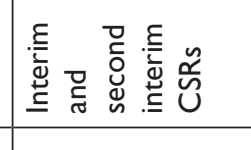 & 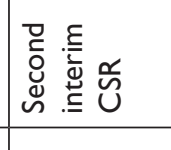 & 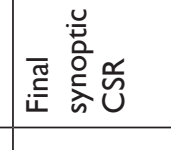 & 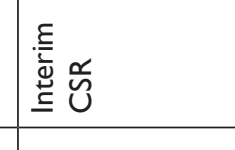 \\
\hline 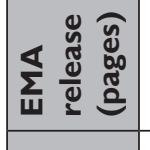 & 胥 & 串竎 & to & 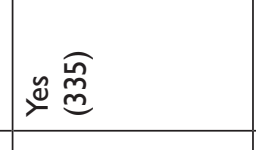 & 米危 & 必 $\widehat{\text { e् }}$ & 承态 \\
\hline 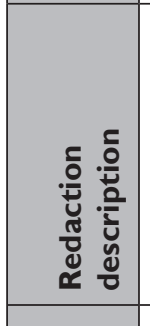 & 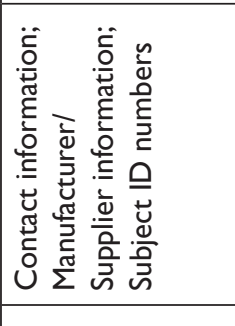 & 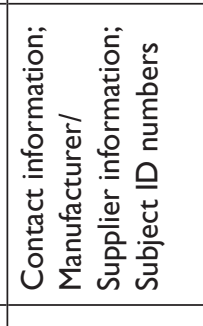 & 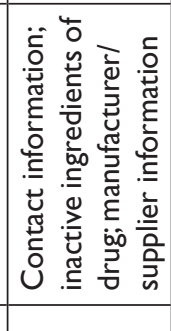 & 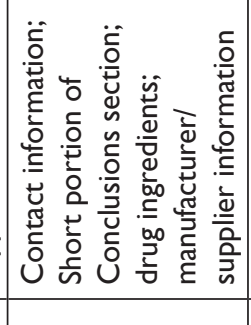 & 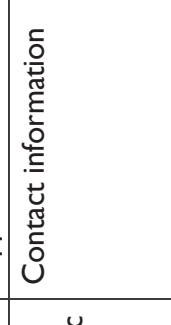 & & 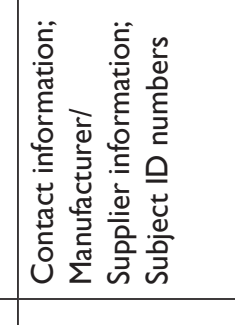 \\
\hline 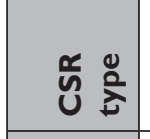 & 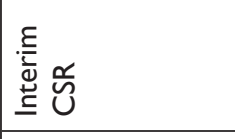 & \begin{tabular}{|l}
$\underline{\underline{E}}$ \\
$\underline{\underline{\underline{y}}}$ \\
$\underline{\underline{\underline{y}}}$ \\
\end{tabular} & 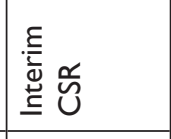 & 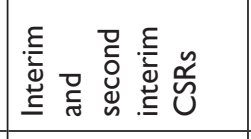 & 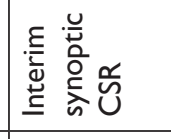 & & 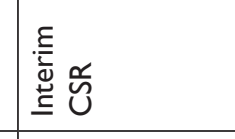 \\
\hline 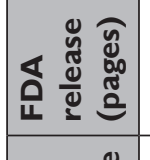 & 递 & 䎹产 & 选 & 总 & 总否 & $\stackrel{\circ}{z}$ & 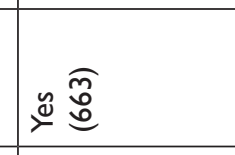 \\
\hline 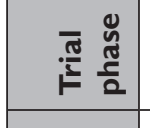 & $\equiv$ & $\equiv$ & $\leqq$ & $\leqq$ & $=$ & $=$ & $=$ \\
\hline 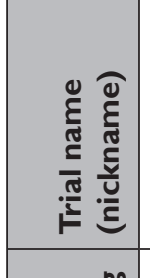 & 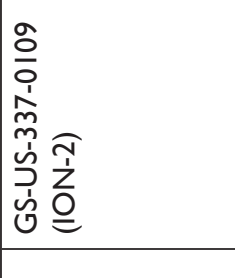 & 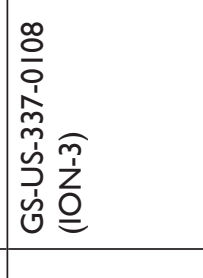 & 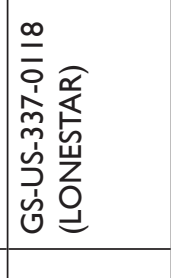 & 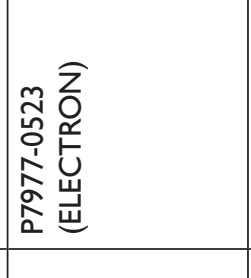 & 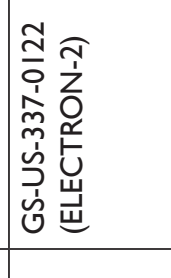 & 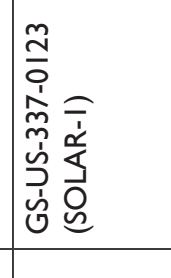 & 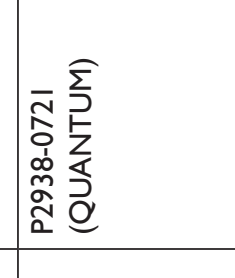 \\
\hline 㕵 & 蒿主 & 㟥主 & 㟥主 & 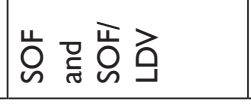 & 蒿至 & 岕怠 & 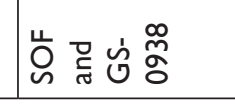 \\
\hline
\end{tabular}




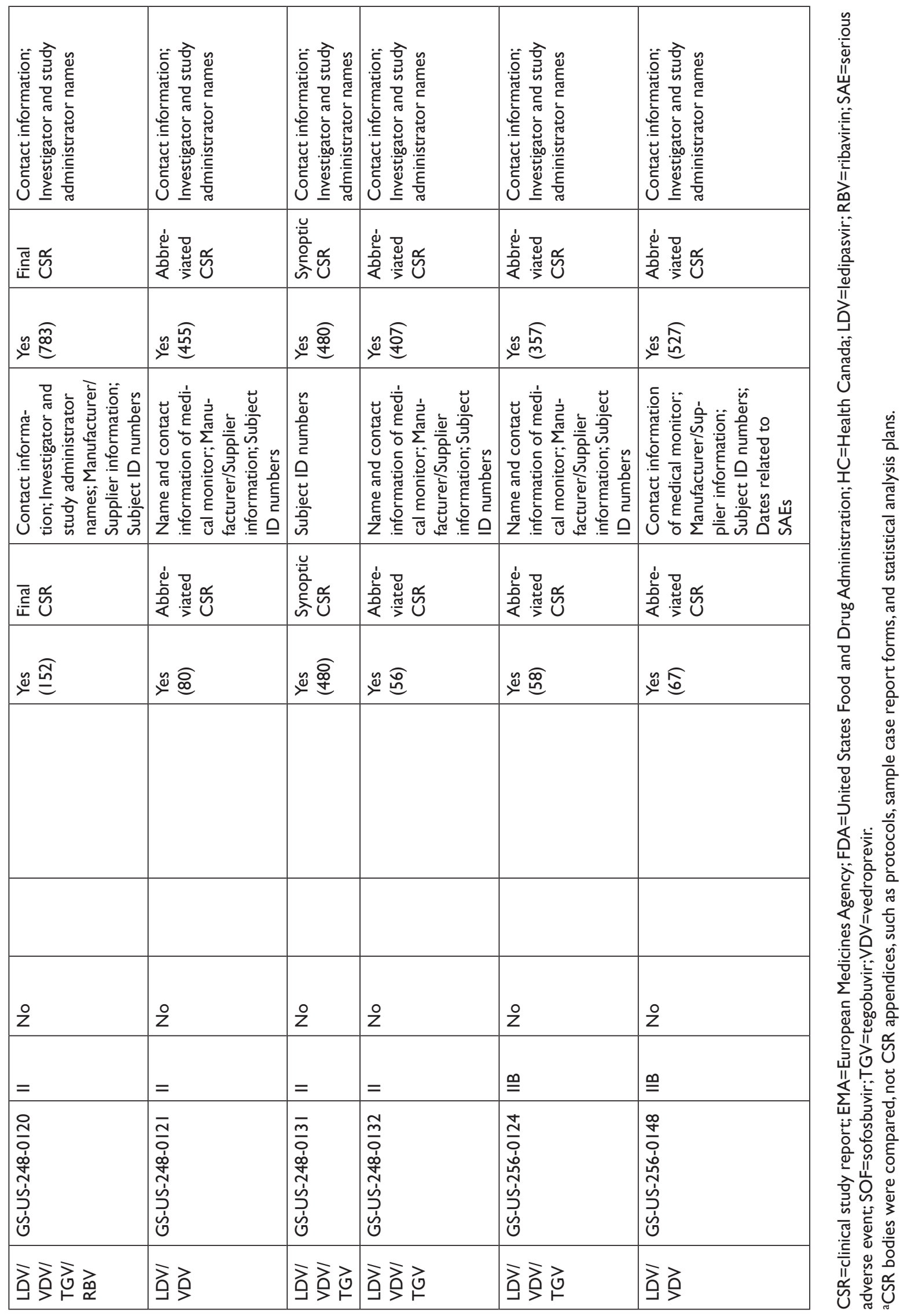

The Journal of Lare, Medicine छ Ethics, 49 (2021): 456-485. (c) 2021 The Author(s) 
AppendixTable 6

Timeline of milestones for our information requests to the European Medicines Agency, Health Canada, and the US Food and Drug Administration

\begin{tabular}{|c|c|c|c|c|c|c|}
\hline Agency & FDA & $\begin{array}{l}\text { FDA } \\
\text { (days) }\end{array}$ & EMA & $\begin{array}{l}\text { EMA } \\
\text { (days) }\end{array}$ & HC & HC (days) \\
\hline Initial request & December 17,2014 & 0 & November 14, 2016 & 0 & February 27, 2020 & 0 \\
\hline Request acknowledged & December 19,2014 & 2 & November 15, 2016 & I & $\mathrm{n} / \mathrm{a}$ & $\mathrm{n} / \mathrm{a}$ \\
\hline $\begin{array}{l}\text { Decision on expedited pro- } \\
\text { cessing request }\end{array}$ & December 22, 2014 & 5 & $\mathrm{n} / \mathrm{a}$ & $\mathrm{n} / \mathrm{a}$ & $\mathrm{n} / \mathrm{a}$ & $\mathrm{n} / \mathrm{a}$ \\
\hline Decision on request & $\mathrm{n} / \mathrm{a}$ & $\mathrm{n} / \mathrm{a}$ & November 18,2016 & 4 & $\mathrm{n} / \mathrm{a}$ & $\mathrm{n} / \mathrm{a}$ \\
\hline $\begin{array}{l}\text { Appeal filed-expedited } \\
\text { processing }\end{array}$ & January 26,2015 & 40 & $\mathrm{n} / \mathrm{a}$ & $\mathrm{n} / \mathrm{a}$ & $\mathrm{n} / \mathrm{a}$ & $\mathrm{n} / \mathrm{a}$ \\
\hline $\begin{array}{l}\text { Appeal decision-expedited } \\
\text { processing }\end{array}$ & February 19,2015 & 64 & $\mathrm{n} / \mathrm{a}$ & $\mathrm{n} / \mathrm{a}$ & $\mathrm{n} / \mathrm{a}$ & $\mathrm{n} / \mathrm{a}$ \\
\hline $\begin{array}{l}\text { Request for reconsideration } \\
\text { of appeal filed }\end{array}$ & April I, 2015 & 105 & $\mathrm{n} / \mathrm{a}$ & $\mathrm{n} / \mathrm{a}$ & $\mathrm{n} / \mathrm{a}$ & $\mathrm{n} / \mathrm{a}$ \\
\hline $\begin{array}{l}\text { 2nd appeal decision-expe- } \\
\text { dited processing }\end{array}$ & April 3,20I5 & 107 & $\mathrm{n} / \mathrm{a}$ & $\mathrm{n} / \mathrm{a}$ & $\mathrm{n} / \mathrm{a}$ & $\mathrm{n} / \mathrm{a}$ \\
\hline Court filing & June 25,2015 & 190 & $\mathrm{n} / \mathrm{a}$ & $\mathrm{n} / \mathrm{a}$ & $\mathrm{n} / \mathrm{a}$ & $\mathrm{n} / \mathrm{a}$ \\
\hline Initial court decision & September 20, 2016 & 643 & $\mathrm{n} / \mathrm{a}$ & $\mathrm{n} / \mathrm{a}$ & $\mathrm{n} / \mathrm{a}$ & $\mathrm{n} / \mathrm{a}$ \\
\hline Initial data production & September 19,2016 & 642 & December I, 2016 & 17 & $\mathrm{n} / \mathrm{a}$ & $\mathrm{n} / \mathrm{a}$ \\
\hline $\begin{array}{l}\text { Agreement to narrow } \\
\text { request }\end{array}$ & November 29, 2016 & 713 & $\mathrm{n} / \mathrm{a}$ & $\mathrm{n} / \mathrm{a}$ & $\mathrm{n} / \mathrm{a}$ & $\mathrm{n} / \mathrm{a}$ \\
\hline Final data production & June 22,2017 & 918 & July 10,2019 & 968 & $\begin{array}{l}\text { July 31, } 2020 \\
\text { (Harvoni) } \\
\text { February 12, 202I } \\
\text { (Sovaldi) }\end{array}$ & $\begin{array}{l}155 \\
\text { (Harvoni) } \\
351 \\
\text { (Sovaldi) }\end{array}$ \\
\hline
\end{tabular}

EMA=European Medicines Agency; FDA=United States Food and Drug Administration; HC=Health Canada. 


\section{Appendix Box 1}

Information requested from the US Food and Drug Administration under the Freedom of Information Act

I. All data submitted in relation to the new drug application ("NDA") for sofosbuvir and the sofosbuvir/ledipasvir combination from the earliest trials onward, including, but not limited to:

- patient-level safety and efficacy data;

- case report forms;

- informed consent forms;

- adjudication forms;

- toxicity and dosage information;

- pharmacology data and formulation;

- records generated by international experience regarding sofosbuvir.

2. All records submitted in support of any associated accelerated NDAs or supplemental NDAs for these drugs.

3. All study protocols submitted along with the raw pre-market approval and post-market adverse event data for sofosbuvir and the sofosbuvir/ledipasvir combination.

4. All records regarding the Breakthrough Therapy Designation priority review of sofosbuvir and the sofosbuvir/ledipasvir combination.

5. All records related to trials and design of trials for sofosbuvir and the sofosbuvir/ledipasvir combination, whether the trial design was approved or not approved.

6. All correspondence between HHS or FDA and the company or companies developing sofosbuvir and the sofosbuvir/ ledipasvir combination, including both Gilead Sciences and Pharmasset, that concern any aspect of the FDA approval process.

7. Any other raw clinical trial data regarding sofosbuvir and the sofosbuvir/ledipasvir combination submitted by Gilead Sciences to the FDA in support of FDA approval.

8. All records, including the Clinical Study Reports, regarding trials of sofosbuvir and the sofosbuvir/ledipasvir combination alone or in combination with another drug or drugs (e.g., ribavirin and/or interferon), including, but not limited to, the following trials:

- SPARE Trial;

- ELECTRON Trial;

- FUSION Study;

- FISSION Study;

- POSITRON Study;

- VALENCE Study;

- NEUTRINO Study;

- PHOTON-I Study;

- ION-I Study;

- ION-2 Study; and

- ION-3 Study. 